NBER WORKING PAPER SERIES

\title{
IS HUMAN-INTERACTION-BASED INFORMATION SUBSTITUTABLE? EVIDENCE FROM LOCKDOWN
}

\author{
Jennie Bai \\ Massimo Massa \\ Working Paper 29513 \\ http://www.nber.org/papers/w29513
NATIONAL BUREAU OF ECONOMIC RESEARCH
1050 Massachusetts Avenue
Cambridge, MA 02138 \\ November 2021, Revised February 2022
}

We thank Fernando Anjos, Turan Bali, David McLean, Chris Parsons, Johan Sulaeman, Laura Veldkamp, and seminar participants at NBER Asset Pricing Spring conference (2021), ABFER 8th annual conference (2021), the Shanghai Financial Forefront Symposium (2021), FTSE/ Russell World Investment Forum, the Santiago Finance Workshop, University of Utah, University of Oregon, NOVA School of Business and Economics, Nanyang Technological University, University of Technology Sydney, Zhongnan University of Economics and Law, and Georgetown University for helpful comments. Tuo Wu provides excellent research assistance. All errors remain our responsibility. The views expressed herein are those of the authors and do not necessarily reflect the views of the National Bureau of Economic Research.

NBER working papers are circulated for discussion and comment purposes. They have not been peer-reviewed or been subject to the review by the NBER Board of Directors that accompanies official NBER publications.

(C) 2021 by Jennie Bai and Massimo Massa. All rights reserved. Short sections of text, not to exceed two paragraphs, may be quoted without explicit permission provided that full credit, including (C) notice, is given to the source. 
Is Human-Interaction-based Information Substitutable? Evidence from Lockdown

Jennie Bai and Massimo Massa

NBER Working Paper No. 29513

November 2021, Revised February 2022

JEL No. G01,G12,G14,G23

\begin{abstract}
We study information substitutability in the financial market through a quasi-natural experiment: the pandemic-triggered lockdown that has hampered people's physical interactions and hence the ability to collect, process, and transmit human-interaction-based information. Exploiting the cross-sectional and time-series variation of lockdown and its implications for proximate investment, we investigate how the difficulty of using human-interaction-based information in lockdown has prompted a switch to non-interaction-based information. We show that lockdown reduces fund investment in proximate stocks and generates a portfolio rebalancing toward distant stocks. Such rebalancing negatively impacts fund performance by reducing fund raw (excess) returns an additional $0.51 \%(0.19 \%)$ per month during lockdown, suggesting that humaninteraction-based and non-interaction-based information is not easily substitutable. Last, we show that the edge of human-interaction-based information originates preeminently from physical contacts, primarily in cafés, restaurants, bars, and fitness centers, and that the virtual world based on Zoom/Skype/Teams cannot substitute for personal meetings in generating sufficient information.
\end{abstract}

Jennie Bai

McDonough School of Business

Georgetown University

3700 O Street, NW

Washington, DC 20057

and NBER

jennie.bai@georgetown.edu

Massimo Massa

INSEAD

Department of Finance

1 Ayer Rajah Avenue, 138676

Singapore

massimo.massa@insead.edu 


\section{Introduction}

Advances in information technology are transforming the way people collect, process, and transmit information. Institutional investors now have access to more data, from traditional financial statements to alternative hi-tech sources such as satellite imagery, geolocation data, social media posts, and credit card transactions. Information is increasingly generated by machines and accessible through computers in a tangible, quantifiable, and codifiable form. Meanwhile, investors can still resort to the old fashion and collect information through human interactions, for example, talking to a local firm's managers and employees or socializing in cafés, restaurants, golf courses, and fitness centers. Unlike the former type, this type of information scarcely leaves a trace and thus is difficult to quantify. One key question is whether human-interaction-based information can be substituted by machine-generated information. Furthermore, is human-interaction-based information tied to physical contacts, or are virtual meetings sufficient to produce it?

These questions are important but difficult to test empirically. The first difficulty is identifying an exogenous shock that affects only one type of information but not the other. The second difficulty in assessing information substitutability is to devise an objective and quantifiable way that can evaluate the "success" of information substitution. Due to these challenges, the literature offers little insight to answer these questions.

In this paper, we exploit a randomized experiment, the pandemic-triggered lockdown that restrained physical contacts and hence exogenously hindered human-interaction-based information collection. Using this natural experiment and exploiting the cross-sectional and time-series variation of lockdown, ${ }^{1}$ we investigate the nature of human-based information and test information substitutability by examining how lockdown restrictions on human interactions have affected the way asset managers resorted to human-interaction-based information. In particular, we focus on proximity investment, behind which soft information is argued to

\footnotetext{
${ }^{1}$ In March 2020, states and counties in the United States started to enforce lockdown. Lockdown varied by geography and time. We use two types of lockdown information. The first is based on executive orders, and the other is based on real business contractions from footprint activities. See Section 3 for further details.
} 
be one of the main drivers according to the local bias literature. Specifically, we test how lockdown has affected fund performance, investment, and risk management for mutual fund managers with a geographical preference for proximate stocks before the pandemic.

The local bias literature has documented that investors of all stripes prefer to hold and trade local stocks. ${ }^{2}$ However, the literature disagrees with the explanations. Some argue that investors prefer proximate stocks to exploit local information edge (e.g., Brennan and Cao, 1997; Obstfeld and Rogoff, 2000; Veldkamp and Nieuwerburgh, 2009). Others claim that the preference of proximate stocks is driven by familiarity and trust (e.g., Huberman, 2001; Seasholes and Zhu, 2010; Pool, Stoffman, and Yonker, 2012). We decompose the sources of local information edge into two parts: one is based on human interactions and the other is not. Referring to human interactions, we further distinguish between physical and virtual interactions. With these refinements, we postulate the following hypotheses.

Our first hypothesis, the "physical human interaction" hypothesis [H1], claims that proximity investment relates to the ability to collect and process information accrued through physical human interactions. Lockdown induces a reduction in social contacts, which hampers the ability to gather and process physical human-interaction-based information. As a result, funds with a geographical preference for proximate stocks will lose their information edge and perform even worse during lockdown than funds investing distantly.

When they lose their information edge due to disrupted physical interactions, fund managers have three possible reactions. First, they can replace in-person meetings with virtual meetings. If virtual meetings can fully substitute for in-person meetings, lockdown should not affect the degree of proximity investment or weaken the local information edge fund managers have secured through previously built connections. However, if funds investing locally perform even worse during lockdown than funds investing distantly, the performance

\footnotetext{
${ }^{2}$ The literature is large and growing. For example, Coval and Moskowitz (1999, 2001); Hau (2001); Choe, Kho, and Stulz (2005); Malloy (2005); Gaspar and Massa (2007); Bae, Stulz, and Tan (2008); Butler (2008); Baik, Kang, and Kim (2010); Korniotis and Kumar (2012); Bernille, Kumar, and Sulaemen (2015); Jagannathan, Jiao, and Karolyi (2018) study the case of mutual fund managers. Teo (2009); Sialm, Sun, and Zheng (2020) provide evidence for hedge fund managers, and Huberman (2001) do so for retail investors.
} 
differentiation would suggest that virtual meetings cannot substitute for physical contacts in generating sufficient information. That is, the human-interaction-based information derives preeminently from physical contacts.

The second reaction is to replace human-interaction-based information with non-humaninteraction-based one. If human- and non-human-based information could be quickly substituted, fund managers with a human-interaction-based information edge should maintain their relative performance with respect to funds investing distantly. The intuition can be understood by considering an equilibrium framework (e.g., Berk and Green, 2004). Some fund managers rely more on human-interaction-based information, while others are more reliant on non-interaction-based information, but in equilibrium, the two information strategies should achieve the same performance. If any difference exists, it would be equalized by the flows into the better-performing funds. Thus, there should be no difference in performance for funds relying more on human information and those on non-human information in equilibrium. ${ }^{3}$ However, any shock to the information collection technology will break the equilibrium and differentiate the performance of funds relying on different information technologies.

Suppose that fund managers realize that virtual meetings cannot generate sufficient information or the transition to non-human-interaction-based information is too costly. In that case, fund managers will respond in a third way. They will be more careful and temporarily retrench into a more passive and less risky portfolio. This implies reduced portfolio concentration and a lower degree of risk-taking.

Our second hypothesis is the "non-human-interaction" hypothesis [H2]: proximity investment relates to a better understanding of the local economy and hence local firms' economic perspectives. Lockdown should not affect the ability to gather and process non-humaninteraction-based information, which is mostly accessible on the internet (also denoted as "hard" information in the literature). For example, a better understanding of the local economy and local firms is obtained through observing satellite imageries, which continue

\footnotetext{
${ }^{3}$ The choice of one technology over the other depends on the cost of information technology and manager skills, although in equilibrium, the performance should not be different.
} 
to work during lockdown. Under this hypothesis, lockdown should not influence the degree of proximate investment or increase the relative benefits of distant investment to proximate investment.

The third hypothesis is the "behavioral bias" hypothesis [H3]: proximity investment relates to behavioral bias such as familiarity and trust. Individual and institutional investors tend to invest in companies nearby since they feel more familiar with them (e.g., Huberman, 2001). Familiarity breeds confidence, reduces risk aversion, and increases the willingness to hold related assets (Hong, Kubik, and Stein, 2005; Pool, Stoffman, and Yonker, 2012). ${ }^{4}$ Other non-information-based behavioral explanations include the case in which investors tend to trust local companies, and local investors feel it an honor or a responsibility to invest in the local community (e.g., Lai and Teo, 2008; Strong and Xu, 2003). For all behavioral explanations, the reduction in social interactions should not affect behavioral bias since existing familiarity, trust, and responsibility are persistent. Therefore, lockdown should have no additional impact on fund behavior; any significant results on fund investment or performance will favor an information-based explanation for proximity investment.

To test the three hypotheses, we rely on the combined findings of the impact of lockdown on fund performance, portfolio allocation, and risk management. We employ a differencein-difference method during the period 2019-2020 to examine the implications of a fund's pre-pandemic geographical preference on fund investment and performance during lockdown.

Starting with fund performance, we document that, all else being equal, funds investing locally before the pandemic tend to perform even worse during lockdown than funds investing distantly, whereas the performance of the two types of funds is similar before lockdown. The effect is economically sizable: funds displaying one standard deviation higher average investment distance before the pandemic (as of March 2019) have a 0.51\% higher raw return and

\footnotetext{
${ }^{4}$ Traditionally, familiarity bias is an explanation for both proximity investment and home bias, i.e., the fact that investors invest in stocks from their own countries. Moreover, local investors may ultimately cater to local retail investors and therefore may be subject to different liquidity concerns and flow sensitivities that will induce different and potentially more advantageous liquidity considerations. The positive correlation between local investing and improved liquidity conditions will induce a "spurious" positive correlation unrelated to local stock information.
} 
0.19\% higher excess return per month during lockdown. When using the footprint contraction as the lockdown indicator, the economic significance is even larger: funds displaying one standard deviation higher investment distance than the cross-sectional average as of March 2019 have a $0.64 \%$ (0.29\%) higher raw (excess) return per month during lockdown. Similar results hold when fund performance is measured by the alpha based on the five-factor model in Fama and French (2015) or by the return gap in Kacperczyk, Sialm, and Zheng (2008) which captures the performance due to unobserved actions. The combination of the undifferentiated performance before the pandemic and the performance differentiation during lockdown indicates that funds investing locally lose their human-information-based information edge during lockdown. Thus, the result rejects the non-human-interaction hypothesis (H2) and the behavioral bias hypothesis (H3) since lockdown mainly disrupts information collection through physical human interactions while exerting little influence on non-interaction-based information collection or familiarity.

We repeat the above test using a paired fund sample to address the concern that the local-investing funds had even worse performance because the local regions suffered more economically during lockdown. In this sample, two funds are paired in the same region, say within 20 miles, but they have different degrees of footprint activities and hence different levels of social interactions. We robustly find that the local-investing funds underperform the distant-investing funds during lockdown. Meanwhile, the two funds in each pair do not differ significantly in performance. These findings indicate that the different degrees of social interaction reduction are the primary factor driving fund performance rather than local economic conditions. Hence, they again rejects the non-human-interaction hypothesis (H2).

The fund performance results support the physical human interaction hypothesis (H1). They also suggest a lack of swift substitutability between information collected through physical human interactions and from alternative sources. Next, we examine how fund managers react to the loss of a physical human-interaction-based information edge. We find that funds investing locally before the pandemic trim down investments in proximate stocks during 
lockdown and tilt their portfolios toward distant stocks. Specifically, if a firm's distance to its holding fund is one standard deviation lower than the cross-sectional average fund-firm distance, we will observe a $0.83 \%$ decrease in the fund's portfolio weight on the specific stock and a $0.35 \%$ decrease in the excess weight deviated from the benchmark index. That is, if a stock's issuing firm is 100 miles closer to the holding fund, funds on average will reduce the portfolio (excess) weight on this stock by $0.10 \%(0.04 \%)$ during lockdown. The results are similar when using the footprint contractions as the lockdown indicator. The results also remain robust after controlling for the time-varying firm, fund, and industry information such as firm return, firm characteristics, lockdown information from firm-located and fund-located zip codes, and fund, firm, and industry $\times$ time (year-month) fixed effects.

A snapshot of portfolio composition further suggests that for the local-investing funds, the firms in which they increase investment during lockdown are on average $24.08 \%$ more distant than those in which they reduce investment. The firms they newly invested in during lockdown are on average 12.87\% farther away than the firms from which they divested.

The above portfolio adjustment has two potential explanations: one favors the loss of an information edge leading to decreased investment in related stocks, and the other suggests exploiting information edge of local firms with negative perspectives and therefore underweighting related stocks. To distinguish two explanations, we calculate the activeness in proximate stocks and find that the local-investing funds significantly reduce the activeness in proximate stocks during lockdown, and more so than the distant-investing funds. This rules out the explanation of exploiting the local information edge. Instead it suggests that the decrease in the portfolio weights of proximate stocks is due to the local-investing funds losing the physical human-interaction-based information edge. A seemingly natural substitute of virtual meetings on Zoom/Skype/Teams cannot provide sufficient information unlike physical contacts. ${ }^{5}$

\footnotetext{
${ }^{5}$ The question of why virtual meetings cannot generate sufficient information while in-person meetings can is interesting, although not the object of this paper. Studies in psychology have demonstrated the importance of human touch and nonverbal communication.(e.g., Mehrabian, 1972, 1981). Anecdotes suggest that virtual meetings could be recorded or potentially hacked, which discourages communicating private and
} 
Additional analyses on fund investment show that for the local-investing funds, their newly-invested stocks in lockdown have more "tangible" information than the divested stocks: they have a smaller dispersion of analyst forecasts and smaller forecast errors. In contrast, the distant-investing funds do not significantly adjust portfolios toward stocks with more tangible information. Using the reliance-on-public-information (RPI) measure in Kacperczyk and Seru (2007), we also find that the local-investing funds significantly increase their RPI by 34.6 percent from March 2019 to March 2020. The increase is both statistically and economically significant. However, the distant-investing funds do not increase RPI in a statistically significant way.

These investment adjustments suggest that after losing the physical human-interactionbased information edge, the local-investing funds attempt to use more hard information. In contrast, the pandemic lockdown did not significantly affect the information technology of the distant-investing funds, and hence they have no motivation to change their investments. However, the combined evidence on fund investment and performance indicates that switching from human-based to non-human-based information is not successful. Ultimately, hard information was not the revealed preference for the local-investing funds before the pandemic. It takes time and money to switch to a new information technology.

Does the failure of effectively replacing physical human-interaction-based information with virtual-interaction-based or non-human-interaction-based information induce mutual fund managers to take precautionary measures? We expect that the ineffective information substitutability will lead to less willingness to take risk. We indeed find that the localinvesting funds become more passive. Compared to the distant-investing funds, they reduce their activeness in proximate stocks by narrowing the deviation of their investment from their benchmarks' investment. Moreover, they reduce portfolio concentration and risk-taking. Using the risk-shifting measure inspired by Huang, Sialm, and Zhang (2011), we show that as the lockdown shock hits the market, the local-investing funds take more actions to reduce confidential information. 
risks. The impact on their portfolios is both statistically and economically significant.

Lastly, we focus on the nature of human-interaction-based information and ask where such information originates. We exploit 3.6 million commercial points of interest with NAICSidentified categories and examine which industry's footprint contraction has the most salient impact on fund performance. Our findings point to a "human touch" channel such as cafés, restaurants, drinking places, and fitness centers.

Overall, our findings document that mutual fund managers partially resort to humaninteraction-based soft information to invest in proximate stocks. However, such information is acquired mostly through physical contacts and thus diminishes when social interactions become hampered during lockdown. Consequently, fund managers tend to invest less in proximate stocks, rebalance portfolios toward distant stocks, and rely more on non-interactionbased information. Nevertheless, such transition leads to further deteriorated performance, highlighting that the cost of adapting to new information is high, and thus human- and nonhuman-based information cannot be easily substituted. Given the high transition costs, the

local-investing funds become more passive, diversifying their portfolios and reducing fund risks.

In the next section we discuss our contributions to the literature. Then we describe the data, construct the key variables, test the hypotheses, and present the main results.

\section{Contribution to the Literature}

Our study contributes to several strands of the literature. The first strand relates to the literature on hard and soft information (Aghion and Tirole, 1997; Stein, 2002; Petersen, 2004; Liberti and Petersen, 2019). The differentiation of hard and soft information is also documented in the banking and organizational literature, where hard information is defined as codifiable and easily transmissible within complex organizations (e.g., Berger et al., 2005; Liberti and Mian, 2009). We contribute to the literature by refining the concept of "soft" 
information and highlighting its inherent link to "human touch." Using an ideal natural experiment in which the pandemic-triggered lockdown uniquely curtails physical interactions, we show that soft information is essentially related to human physical contacts. The virtual world based on Zoom/Skype/Teams and remote connections cannot produce sufficient soft information. From this perspective, our paper also offers a clear identification for the social interaction literature, which highlights the important role of personal interactions for investors (e.g., Shiller and Pound, 1989; Hong, Kubik, and Stein, 2005; Han, Hirshleifer, and Walden, 2021; Brogaard, Ringgenberg, and Roesch, 2021).

Second, we identify the source of the local preference for the local bias literature. It has been documented that investors tend to invest more in the assets of companies located nearby. This is the case for mutual fund managers (e.g., Coval and Moskowitz, 1999, 2001; Hau, 2001; Choe, Kho, and Stulz, 2005; Malloy, 2005; Gaspar and Massa, 2007; Bae, Stulz, and Tan, 2008; Butler, 2008; Baik, Kang, and Kim, 2010; Korniotis and Kumar, 2012; Bernille, Kumar, and Sulaemen, 2015; Jagannathan, Jiao, and Karolyi, 2018), hedge fund managers (Teo, 2009; Sialm, Sun, and Zheng, 2020) and retail investors (Huberman, 2001). The existing literature offers two alternative explanations for the preference for local stocks. Some argue that investors prefer to buy local stocks to exploit their local information edge (Brennan and Cao, 1997; Obstfeld and Rogoff, 2000; Veldkamp and Nieuwerburgh, 2009). Other studies find that the local bias is driven by behavioral bias such as familiarity and trust (Huberman, 2001; Seasholes and Zhu, 2010; Pool, Stoffman, and Yonker, 2012).

We contribute to this literature along two dimensions. First, we disentangle the explanations of proximity investment and show that mutual fund managers resort to humaninteraction-based soft information to invest in proximate stocks. Second, we show that such information is inherently linked to physical contacts and is not necessarily related to geographical proximity. Proximity facilitates collecting human-interaction-based information, but it is not a necessary condition. As shown in the pandemic-triggered lockdown environment, being local but having no physical interactions cannot generate an information edge. 
Our findings also reconcile with those of the "air travel distance" literature. Da, Gurun, Li, and Warachka (2021) show that air travel can stimulate indirect word-of-mouth communication and social interactions and hence reduce local investment bias. Bernstein, Giroud, and Townsend (2015) show that direct flights help enhance the venture capitalists' on-site monitoring by increasing interactions with their portfolio companies and management. Our paper provides direct evidence suggesting that the key factor for gaining an information edge is not distance but rather physical human interactions.

Third, our study adds to the fast-growing literature on information production. Many recent papers emphasize the role of big data and the technology of machine learning in generating valuable information (e.g., Begenaua, Farboodi, and Veldkamp, 2018; Grennan and Michaely, 2020; Zhu, 2019). We complement this literature by emphasizing the value of information collected through physical human interactions. We further show that non-humaninteraction-based information such as those generated by machines cannot easily substitute information collected through human interactions.

Finally, our study relates to the burgeoning literature on the COVID-19 pandemic crisis. Most of this literature studies the impact of the pandemic crisis on the various dimensions of the capital market. We focus on the information distortion in the crisis. Earlier studies document the retrenchment effect whereby investors are more likely to liquidate geographically remote investments at times of high market volatility (Giannetti and Laeven, 2016). Our paper finds the opposite: investors rebalance portfolios toward distant investments during lockdown when market volatility is high. We show that the retrenchment to passive risk management is due to the loss of the human-interaction-based information edge and the difficulty of switching to alternative information technologies. 


\section{Data and Main Variables}

\subsection{Mutual Fund Data}

Our primary data source is the CRSP survivor-bias-free mutual fund database. We focus on domestic actively-managed open-end equity mutual funds. To examine fund portfolio allocations, performance, and risk management before and during the pandemic lockdown, we consider a sample period from January 2019 to June 2020. As we will explain in the next subsection, the executive order of pandemic lockdown happened mostly in March and April of 2020, and then most states began a multi-phased reopening plan in the summer of 2020 . We end the sample in June 2020 to guarantee that we have an uncontaminated window to test the impact of lockdown. ${ }^{6}$

To select the qualified funds, we first eliminate index, ETF, balanced, bond, money market, international, and sector funds. We then exclude funds that do not invest primarily in equity, holding less than $50 \%$ in common and preferred stocks. We also exclude funds that hold fewer than ten stocks and those that, in the previous month, managed less than $\$ 1$ million assets. For funds with multiple share classes, we eliminate duplicated funds with identical portfolio holdings. We compute the fund-level total net assets (TNA) as the sum of total net assets across different share classes.

To study portfolio allocations and the performance of proximity investment during the pandemic lockdown, we first need to measure the geographical preference of mutual funds, which is often proxied by the average investment distance, labeled as $A D$. Following Coval and Moskowitz (1999), we compute the average investment distance of fund $m$ from all securities it could have invested in using the excess weight between the fund's weight in a specific stock and the corresponding benchmark index's holding weight in the same stock.

\footnotetext{
${ }^{6}$ It is also of interest to investigate how the uplift of lockdown order influences mutual funds. However, the reopening process contains multiple phases, full of uncertainty and unclear instructions. Therefore, we cannot have a clear setup to test the impact of removing lockdown.
} 
More formally,

$$
A D_{m t}=\sum_{i}\left(\text { Weight } t_{i m t}^{\text {Fund }}-W e i g h t_{i m t}^{\text {Index }}\right) * D_{i m},
$$

where Weight $t_{\text {imt }}^{\text {Fund }}$ represents the actual weight (the proportion of investment) that fund $m$ places in stock $i$ and Weight $t_{i m t}^{I n d e x}$ represents the weight that fund $m$ 's benchmark index fund places in stock $i$ at time $t$. We then compute the distance, $D_{i m}$, between the headquarter of fund $m$ 's management company and the corporate headquarter of stock $i$ as follows:

$$
D_{i m}=\arccos \left\{\cos \left(l a t_{m}\right) \cos \left(l a t_{i}\right) \cos \left(l o n_{m}-l o n_{i}\right)+\sin \left(l a t_{m}\right) \sin \left(l a t_{i}\right)\right\} R,
$$

where lat and lon are the latitudes and longitudes of the headquarters of management companies and firms, and $R$ is the radius of the earth (approximately $6,378 \mathrm{~km}$ ). $D_{i m}$ is a constant for each fund-firm pair since there are no changes of headquarters for either mutual funds or firms during the short sample period.

We obtain the zip codes of mutual fund management companies from MorningStar and those of corporate firms from Compustat. For each zip code, we further collect its latitude and longitude values from OpenDataSoft. ${ }^{7}$ With this information, we calculate the spherical distance $D_{i m}$.

To identify a fund's benchmark index, we retrieve fund-level benchmark information from MorningStar. We consider all three indicators: one is according to a fund's prospectus disclosures (Primary_Prospectus_Benchmark), and the other two are according to the benchmark assignment by MorningStar according to its assessment of a fund's investment strategy (FTSE/Russell_Benchmark, and SP_DowJones_Benchmark). Our final choice of benchmark indexes consists of Russell 1000, Russell 2000, Russell 3000, Russell MidCap, and S\&P 500 .

For each fund, we download its monthly return from the CRSP mutual fund dataset. Only funds that report monthly net-of-fee (management, incentive, and other expenses) returns

\footnotetext{
${ }^{7}$ https://public.opendatasoft.com/explore/dataset/us-zip-code-latitude-and-longitude/table/
} 
are kept in the sample. We address the incubation bias in the data by excluding the first12-month fund monthly returns (Elton, Gruber, and Blake, 2001). We define excess return as a difference between the fund return and its benchmark index's return at the monthly frequency. We also calculate a fund's active share following Cremers et al. (2016), which captures the proportion of a fund's holdings that differs from its benchmark index. ${ }^{8}$ We require a fund to have at least $50 \%$ active share to be qualified as active funds in our sample. The $50 \%$ cutoff is somewhat arbitrary, but as, on average, half the holdings (by asset weight) in any portfolio will beat the portfolio's average return, an active fund (with a manager who tries to beat the benchmark) should have an active share of at least 50\%. Finally, we also collect the organizational structure information of mutual funds from MorningStar, including the indicator of whether a fund uses sub-advisors.

\subsection{The Pandemic Lockdown Information}

Since March 2020, states and counties in the United States have started to enforce lockdown. Lockdown varied by geography and time, involving different rules from restrictions on having meals with other people in public places to the extreme of stay-at-home orders. ${ }^{9}$ Lockdown exogenously affected non-essential workers including fund managers, and greatly reduced, if not completely blocked, their ability to gather soft information through socializing with other people.

We collect two types of lockdown information. The first type is based on whether a zip code has had an executive order of lockdown and, if so, the start date of lockdown based on the government announcement. The lockdown order is mostly issued at the state level, which

${ }^{8}$ The formula to calculate active share is as follows:

$$
\text { ActiveShare }_{m t}=\frac{1}{2} \sum_{i}\left|W e i g h t_{i m t}^{\text {Fund }}-W e i g h t_{i m t}^{\text {Index }}\right|,
$$

where Weight $t_{\text {imt }}^{\text {Fund }}$ and Weight $t_{\text {imt }}^{\text {Index }}$ are the portfolio weights of stock $i$ in fund $m$ and its benchmark index, respectively, and the sum is taken over the universe of stocks at a given month $t$.

${ }^{9}$ Alternative descriptions to lockdown include curfews, quarantines, stay-at-home orders, shelter-in-place orders, and cordons sanitaires. We use the general word "lockdown" to describe the various degrees of social isolation. 
has power for all zip codes in a given state. Nevertheless, there are also a few exceptions in which the order was issued at a different date by local counties, for example, Davis County and Salt Lake County in Utah. Most of the 50 states issued the order of lockdown during the pandemic, but six states did not: North Dakota, Iowa, Arkansas, Nebraska, South Dakota, Wyoming. We set a dummy variable, Lockdown $n_{m t}$, which is equal to 1 if the lockdown order is effective in a given month $t$ for a zip code in which fund- $m$ 's management company is headquartered, and 0 otherwise.

The second type of lockdown information comes from the foot traffic data collected by SafeGraph, which captures the real business activities. The data, generated using a panel of GPS pins from over 45 million mobile devices to 3.6 million commercial points-of-interest in the United States, describes the number of people's visits to certain places during certain time intervals. The population sample is a panel of opt-in, anonymous smartphone devices. It is well balanced across USA demographics and geographies, covering roughly $10 \%$ of the US population. ${ }^{10}$ We select data from January 2019 to June 2020, then merge the footprint data with the brand information, which includes the industry code, primary and second categories of 5916 brands in 30434 zip codes, based on SafeGraph brand IDs. As a result, we know how often people go to certain brands during certain time intervals in a zip code.

We construct a dummy variable, Footprint $t_{m t}$, which is equal to 1 for fund $m$ in a given month $t$ if footprint activities in the fund-located zip code contracted $30 \%$ relative to the activities in the same zip code in March 2019 (one year before the start of lockdowns across the country). ${ }^{11}$ This second type of lockdown proxy is a good supplement to the first one since not every state has issued the lockdown order. Thus, mutual funds in those areas cannot be evaluated for their performance during lockdown based on the first type of lockdown

\footnotetext{
${ }^{10}$ SafeGraph has conducted a series of tests to address the concern of sampling bias. One test calculates the Pearson correlation between the number of devices and the census population across 3281 counties in the United States, and the correlation is as high as $97 \%$. For more details, please see the link https://colab. research.google.com/drive/1u15afRyt JMsizySFqA2EP1XSh3KTmNTQ\#offline=true\&sandboxMode=true.

${ }^{11}$ The threshold, $-30 \%$, is the 75 th percentile value of the percentage change of footprint activities across all zip codes in our sample between March 2020 and March 2019. We also conducted a robustness check using the mean and the median value, both are $-40 \%$, and all results hold. Figure 1 plots the histogram of the percentage change of footprint activities in lockdown.
} 
information. Moreover, the executive orders of lockdown are voluntary and not necessarily strictly enforced, while the real business activities captured by footprints can more accurately reflect the degree of physical interactions. Lastly, footprint activities provide rich information to explore various channels of physical interactions, as we explain below.

We try two different classifications to explore how footprint activities have changed across industries. The first one classifies all brands into 13 gross industries based on the first two digits of codes in the North American Industry Classification System (NAICS). For example, if the first two digits of the NAICS code are 72, we consider it as accommodation and food services. Second, we consider 11 subcategories based on the four and five digits of NAICS codes, which are more likely related to information transmission. It includes drinking places (alcoholic beverages), personal care services, amusement parks, arcades, etc. We also combine cafeterias, limited-service restaurants, snack and non-alcoholic beverage bars as one category and combine bowling centers, golf courses, and country clubs.

\subsection{Descriptive Statistics and Preliminary Evidence}

We begin our analysis by examining the summary statistics. In Panel A of Table 1, we report the statistics of fund performance and the main characteristics of the actively managed US equity funds in our sample.

Comparing the period before lockdown to the period during lockdown, we see that the average performance of funds drops drastically from $2.22 \%$ to $-1.21 \%$ for fund returns and from $-0.05 \%$ to $-0.10 \%$ for excess returns. The average fund AUM also drops from $\$ 2.29$ billions to $\$ 2.15$ billions. Moreover, the mean value of fund investment distance based on the excess weight increases slightly, the average degree of fund active share decreases, and fund concentration increases, but none of the changes is significant.

In Panel B, we provide the pandemic lockdown information. Thirty-three states issued the executive orders of lockdown in March 2020, and another twelve states joined the list in April 2020. As a result, footprint activity, defined as the total number of visits (in millions) 
within a month for a specific zip code, drops significantly from an average of 0.156 million visits in December 2019 to 0.025 million visits in April 2021 when lockdown is in full swing. Then footprint activities start recovering gradually and slowly but not significantly in May and June 2020.

Figure 1 illustrates the evolution of footprint activities, which captures the real business activities and proxies for the degree of social interaction. Panel A shows the mean and median values of the total footprint activity aggregated across all zip codes in which mutual fund management companies in our sample are located. As we can see, business activities were stable before lockdown but plunged as lockdown started since March 2021. It recovered slightly in May and June 2021 but was still far below the pre-lockdown level.

Panel B reports the histograms of the percentage change of total footprint activities. Since most states started lockdown in March and April of 2021, we calculate the percentage change between March (April) of 2019 and March (April) of 2020. The histograms provide a clear picture of how footprint activity plunked due to lockdown. Across 243 zip codes in our sample, the percentage change of footprint activities in March 2020 relative to March 2019 is on average $-40 \%$, with the median value of $-40 \%$, the standard deviation of $17 \%$, and the 75th percentile of -30\%. The change between April 2019 and April 2020 is even large, with the mean value of $-73 \%$ and the standard deviation of $30 \%$. In short, both figures describe a situation in which business activity went down drastically and hence the reduction of social interactions.

\section{The Implications for Fund Performance}

We start by examining the implications of pre-pandemic geographical preference on fund performance during lockdown. If the preference for local stocks were driven by the nonhuman-interaction hypothesis (H2), that is, mutual fund managers have better information about the local economy and local firms that are not collected through human interactions, 
then we would expect no differential change in performance for the local-investing versus the distant-investing funds during lockdown. If the preference for local stocks were dictated by the behavioral bias hypothesis (H3), that is, fund managers feel more familiar with local companies, then we would also expect no performance differentiation. In both cases, lockdown exerts little impact since non-interaction-based information is mostly accessible on the internet or from public sources, and managers' familiarity was accumulated before the pandemic and persists over the short window in our sample. However, if the preference for local stocks is due to physical human-interaction-based information (H1), we would expect a deteriorating performance of the local-investing funds since lockdown severely disrupted social interactions and hence the collection of physical-interaction-based information.

To test the above conjectures, we examine fund performance using several proxies. The first proxy is a fund's raw return and its excess return with respect to the benchmark index. The second performance measure is the risk-adjusted return, alpha, based on the five-factor model in Fama and French (2015). The third proxy captures the unobserved actions of mutual funds, the return gap in line with Kacperczyk, Sialm, and Zheng (2008). Lastly, we repeat the test using a paired fund sample. Each pair of funds is located in the same region but has different intensities of footprint contractions in lockdown. The only distinguishing feature for the paired funds is the different degrees of social interaction.

\subsection{Fund Return}

We employ the difference-in-difference method to examine fund performance before and during lockdown in the window from January 2019 to June 2020 using the following regression:

$$
\operatorname{Ret}_{m t}=\alpha+\beta * \text { Lockdown }_{m t}+\gamma * A D_{m}^{\text {Mar2019 }} \times \text { Lockdown }_{m t}+\alpha_{m}+\alpha_{t}+\varepsilon_{m t} .
$$

The dependent variable is either a fund's raw return or excess return after deducting its benchmark index's return. $A D_{m}^{\text {Mar2019 }}$ quantifies fund $m$ 's average distance to all the securities 
it could have invested in by using the excess weight between the fund's weight in a given stock and the corresponding benchmark index's holding weight in the same stock, as defined in Equation (1). We use the fund-level investment distance as of March 2019 to capture a fund's pre-pandemic geographical preference. We consider two proxies for lockdown in fund $m$-located zip code in a given month $t$ : the dummy variable Lockdown $_{m t}$ indicates executive orders by governments and the dummy variable Footprint F $_{m}$ indicates the contraction in real business activities. These two dummy variables capture the time-varying economic conditions in fund $m$ 's zip code. We control for the fund fixed effect and the time (year-month) fixed effect. Standard errors are clustered at the fund's management company level. Note that the regression does not include the fund's pre-pandemic geographical preference, $A D_{m}^{M a r 2019}$, since this fund-specific variable is a constant and absorbed by the fund fixed effect.

Table 2 reports the regression results. In Columns (1)-(4), note the negative relationship between lockdown and fund performance, which is particularly strong in terms of economic and statistical significance when lockdown is measured by the contraction of footprint activities. This finding is consistent with the stock market crash during the pandemic. When the U.S. went into lockdown, most actively managed mutual funds experienced poor performance and underperformed their passive benchmarks (Ľuboš Pástor and Vorsatz, 2020).

The parameter of interest is the coefficient on the interaction term between lockdown and a fund's pre-pandemic geographical preference. We find that funds investing locally before the pandemic tend to have worse performance during lockdown. This result is statistically strong and economically large across all regression specifications and for both fund returns and excess returns. In particular, funds displaying one standard deviation higher investment distance in the cross-section before the pandemic (as of March 2019) have a 0.51\% higher raw return and $0.19 \%$ higher excess return per month during lockdown. When using the footprint dummy as the lockdown indicator, the economic significance is even larger: funds displaying one standard deviation higher average investment distance before the lockdown (as of March 2019) display a $0.64 \%$ (0.29\%) higher raw return (excess return) per month 
during lockdown.

These results show that lockdown exerts a differential influence on mutual funds with different pre-pandemic geographical preferences: the local-investing funds suffer more than the distant-investing funds during lockdown. This finding is consistent with the physical human interaction hypothesis since funds exploiting such information can no longer collect this information through social interactions during lockdown. This finding also suggests that the information collected through virtual interactions cannot produce sufficient information to substitute for the information originating from physical contacts.

The timing of fund performance differentiation for the local-investing and distant-investing funds coincides with the lockdown shock and does not seem to reflect a pre-existing trend. Figure 2 plots the point estimates of the impact of the pre-pandemic fund investment distance on fund performance three months before and after the lockdown shock. Again, there is no pre-existing trend. Before the lockdown, the distant-investing funds were no more likely to perform better than the local-investing funds, suggesting that investment distance was not a key factor in differentiating fund performance. The finding of no difference in performance before the pandemic is consistent with the intuition in Berk and Green (2004). However, when lockdown interrupts information technology by reducing physical interactions, the difference in performance for the local-investing and the distant-investing funds becomes significant, with the latter outperforming the former. The gamma estimates are $0.0019(s=t+1)$, $0.0006(s=t+2)$, and $0.0013(s=t+3)$, with corresponding $p$-values of $0.000,0.090$, and 0.001. The precise timing again suggests that lockdown triggers the change in information technology, affecting the performance of funds whose investment strategy relies on human-interaction-based information.

\subsection{Alternative Fund Performance Measure: Alpha}

We now consider another proxy for fund performance, the risk-adjusted return (alpha) and risk exposure (beta). After collecting daily fund returns, we estimate alpha and betas for 
each fund in month $t$ using the Fama-French five-factor model:

$$
\operatorname{Ret}_{m t d}=\alpha_{m t}+\beta_{m t}^{M K T} M k t_{t d}+\beta_{m t}^{S M B} S M B_{t d}+\beta_{m t}^{H M L} H M L_{t d}+\beta_{m t}^{R M W} R M W_{t d}+\beta_{m t}^{C M A} C M A_{t d}+\varepsilon_{m t d},
$$

where $\operatorname{Ret}_{m t d}$ are the daily returns of fund $m$ in month $t$, and $M K T_{t d}, S M B_{t d}, H M L_{t d}$, $R M W_{t d}$, and $C M A_{t d}$ are the daily equity market, size, book-to-market, profitability, and investment factors in Fama and French (2015) in month $t .{ }^{12}$ Then we employ the differencein-difference method to study the change in alpha and betas before and during lockdown in the following regressions:

$$
\begin{aligned}
\alpha_{m t} & =a+b * \text { Footprint }_{m t}+\gamma * A D_{m}^{\text {Mar2019 }} \times \text { Footprint }_{m t}+Z_{m}+Z_{t}+\varepsilon_{m t}, \\
\beta_{m t} & =a+b * \text { Footprint }_{m t}+\gamma * A D_{m}^{\text {Mar2019 }} \times \text { Footprint }_{m t}+Z_{m}+Z_{t}+\varepsilon_{m t} .
\end{aligned}
$$

Table 3 presents the results. Panel A shows that funds on average have negative riskadjusted returns during lockdown as proxied by the contraction of footprint activities, $\alpha=$ -6.39 basis points (bps) per month. However, funds investing locally before the pandemic have an even worse performance, as shown by the positive and significant estimated coefficient on the interaction term, $\gamma=0.0053$ with a $t$-statistic value of 4.31 . Economically, a one standard deviation cross-sectionally higher fund investment distance as of March 2019 is associated with a 1.71 bps per month higher alpha. Moreover, funds investing locally before the pandemic also have significantly higher risk exposure to the risk factors $S M B$ and $C M A$ during lockdown.

Panel B conducts a T-test of the alphas before and during lockdown for the local-investing and the distant-investing funds. We sort funds into quintile portfolios based on their prepandemic investment distance, $A D_{m}^{M a r 2019}$. We label funds with the short investment distance in Portfolio AD_1 as the local-investing funds (LIF) and those with the long investment distance in Portfolio AD_5 as the distant-investing funds (DIF). In March 2019, the local-

\footnotetext{
${ }^{12}$ The $M K T, S M B, H M L, R M W$, and $C M A$ factors of Fama-French (2015) are obtained from the data library of Ken French (http://mba.tuck.dartmouth.edu/pages/faculty/ken.french/).
} 
investing funds had an average alpha value of $1.47 \mathrm{bps}$ per month, while the distant-investing funds have a negative alpha of $-0.57 \mathrm{bp}$. However, the situation reversed in March 2020. The distant-investing funds exhibit a positive performance ( $\alpha=0.18 \mathrm{bp})$ while the localinvesting funds exhibit a negative performance $(\alpha=-3.08 \mathrm{bps})$. A formal $T$-test for the change in the mean value of alphas further suggests that the deterioration of the localinvesting funds' performance is statistically significant, with a $p$-value of 0.00 . In contrast, the improvement of the distant-investing funds' performance is insignificant, with a $p$-value of 0.39. These findings indicate that the differential effect of lockdown across mutual funds is mainly driven by the worse performance of the local-investing funds. The findings also suggest that investing far away is a source of competitive advantage during lockdown when the collection and transmission of human-interaction-based information is curtailed.

\subsection{Unobserved Actions}

One key dimension of performance related to information is possibly not about buying and holding but rather about actively trading on the information. Despite extensive disclosure requirements, mutual fund investors do not observe all actions of fund managers. Indeed, as Bernille, Kumar, and Sulaemen (2015) have shown, a significant amount of proximity-related information translates into a fund's performance through active trading. In this subsection, we investigate the unobserved actions of mutual funds using an alternative performance measure, the return gap, following Kacperczyk et al. (2008).

For each fund in each month, we calculate the return gap as the difference between the

reported fund return $\left(\operatorname{Ret}_{m t}\right)$ and the return on a hypothetical portfolio $\left(\operatorname{Ret}_{m t}^{H}\right)$ that invests in the previously disclosed fund holdings:

$$
\operatorname{ReturnGap}_{m t}=\operatorname{Ret}_{m t}-\operatorname{Ret}_{m t}^{H},
$$


where

$$
\operatorname{Ret}_{m t}^{H}=\sum_{i=1}^{n} \text { Weight }_{i m t-1} * \text { FirmRet }_{i t} .
$$

After calculating the return gap, we focus on the local-investing and the distant-investing funds and examine their different responses before and after the lockdown shock:

$$
\text { ReturnGap }_{m t}=\alpha+\sum_{s=t-3}^{t+3}\left(\beta_{s} * \text { Event }_{m s}+\gamma_{s} * \text { LIFD } D_{m} \times \text { Event }_{m s}\right)+\alpha_{m}+\alpha_{t}+\varepsilon_{m t} .
$$

Event $_{m s}$ is a dummy variable indicating months relative to the fund-specific lockdown shock. When $s=t$, it refers to the year-month when the zip code where fund $m$ is headquartered becomes subjective to an executive lockdown order. $L I F D_{m}$ is a dummy variable for the local-investing funds, which is equal to one if a fund invests more in local stocks (in Portfolio $A D \_1$ ) before the pandemic, and zero if a fund invests more in distant stocks (in Portfolio $\left.A D \_5\right) . \quad \alpha_{m}$ and $\alpha_{t}$ refer to the fund fixed effect and the year-month fixed effect. The coefficients of the interaction terms $\left(\gamma_{s}\right)$ capture the effect of a fund's pre-pandemic geographical preference on the return gap from three months before through three months after the lockdown shock.

Figure 3 plots the point estimates $\left(\gamma_{s}\right)$ and the associated $95 \%$ confidence intervals adjusted for clustering at the fund family level. Confirming the parallel trend of fund excess returns in Figure 2, there is no significant difference in the return gap for the local-investing and the distant-investing funds before the lockdown shock. This corroborates our conjecture that mutual funds use different information technologies and thus have different relative advantages in processing information. When one of the two technologies, say collecting humaninteraction-based information, is suddenly disrupted, the effect of employing such technology becomes observable. The return gap of the local-investing funds is significantly lower than that of the distant-investing funds one month after the lockdown shock and persists for the lockdown period. 


\subsection{Paired Fund Sample}

In this subsection, we reexamine fund performance using a paired fund sample. Two funds are paired if they are located in the same region but are affected differently by lockdown. That is, the two zip codes in the same region have different degrees of footprint activities and hence different levels of social interactions. This sample is ideal for testing the non-humaninteraction hypothesis that the worse performance of the local-investing funds is driven by the deteriorating local economic conditions during lockdown. We first measure the percentage change in footprint activities between March 2019 and March 2020 for each fund's zip code. Then, we define the pair of funds suffering differently from lockdown as those have a difference in footprint contraction of at least 20 percent. For example, one fund's zip code has a $-30 \%$ change in footprint activities while the other's has a $-5 \%$ change. That is, the difference in the footprint contraction is $25 \%$. All funds in pairs have an active share larger than $50 \%$. In each pair, we assign the value of 1 to the fund whose zip code suffers more from lockdown and 0 to the other fund. This indicator variable is labeled Suffer.

When we include all possible pairs that satisfy the above two criteria, (i) sufficient geographically adjacent, and (ii) sufficient variation in the level of social interactions, the sample becomes much larger than that in the main analysis in Regression (3). We repeat the experiment in the main analysis and report the results in Table 4.

We consider two levels of geographical adjacency. The paired funds are located within 100 miles (161 KM) in Panel A and even closer, say within 20 miles (32 KM), in Panel B. The regression specification is the same as in Table 2 except that we use the sample of paired funds and include an additional explanatory variable, the dummy variable Suffer. Again, we find that funds investing locally before the pandemic tend to perform worse during lockdown when fund performance is measured by either the raw return or the excess return. The magnitude of the estimated coefficients are similar to those in Table 2. Moreover, the performance of the fund whose zip code has more business contraction (fewer footprint activities) is not statistically different from that of the other fund in the pair. These findings 
jointly indicate that the decline in social interactions, i.e., the loss of human-interaction-based information, is the primary factor driving fund performance rather than the deteriorating local economic conditions. Thus, they provide additional evidence against the non-humaninteraction hypothesis, indicating that the relatively poor performance of the local-investing funds cannot derive from the fact that the local areas suffer more economically from lockdown.

\subsection{Robust Evidence on the Loss of Information Edge}

Thus far, by focusing on the overall fund performance, we have shown that fund managers lose their physical human-interaction-based information edge during lockdown. In this subsection, we provide the stock-level evidence supporting the loss of information edge. Specifically, we investigate the impact of lockdown on the local-investing funds' information technology by focusing on the predictability of their investment in holding firms. For each stock, we examine fund investment and estimate the predictive power of their local holding funds' excess investment weight on future stock returns:

$$
\begin{aligned}
\text { FirmRet }_{i t+1}= & \alpha+\beta * \Delta \text { ExWeight }_{\text {imt }}^{\text {Local }}+\gamma * \Delta \text { ExWeight }_{\text {imt }}^{\text {Local }} \times \text { FirmLockdown }_{i t} \\
& + \text { FirmLockdown }_{i t}+\text { FirmRet }_{i t}+\alpha^{F E}+\varepsilon_{i t} .
\end{aligned}
$$

$\Delta E x W e i g h t_{i m t}^{L o c a l}$ is the monthly percentage change in excess investment weights by firm $i$ 's local funds. For each firm $i$ in month $t$, we define its "local funds" as those investing in firm $i$ 's stocks and their management companies being within 250 miles of the headquarter of the firm. ${ }^{13}$ To predict a firm's future stock return, we control for the firm's current return and the time-varying economic condition in the firm's zip code proxied by the two-way fixed effect, FirmLockdown ${ }_{i t}$. We also include the industry, firm, and fund $\times$ time fixed effects.

\footnotetext{
${ }^{13}$ Another way to identify local funds is to focus on funds located in the same state as the firm. This measure however is not necessarily better. Locality is more related to geographic distance than administrative division. For example, funds across the Hudson River in New Jersey are more local to holding firms in Bronx, New York City, than funds in Buffalo, New York State, which is about 400 miles from Bronx. We consider a radius of 250 miles to define the locality since it is roughly the distance covered in one-hour of flight by jet airliners and is also a reasonable driving distance by cars.
} 
Standard errors are clustered at the fund $\times$ time and industry level.

Table 5 presents the results. We find that when using either proxy for firm lockdown, the restriction of physical interactions reduces the extent to which local funds' excess investment weights can predict future stock returns. Before the pandemic, the percentage change in local funds' excess investment weights relative to its benchmark index's weights has a significant and positive predictive power on stock returns. However, during lockdown, the net predictive power falls to zero. These findings confirm that lockdown triggered the loss of humaninteraction-based information edge for funds investing nearby.

\section{Lockdown and Proximity Investment}

The results on fund performance alone cannot depict the whole picture. In this section, we examine the impact of lockdown on fund investment to analyze the substitutability of human-interaction-based information. In particular, we diagnose how funds that invested in proximate stocks before the pandemic changed their portfolio allocations during lockdown. First, we employ the difference-in-difference method to examine how a fund adjusts investment in holding firms' stocks during lockdown given its distance to each firm. Then, we consider the overall change in the fund-firm distances for the local-investing and the distantinvesting funds during lockdown. Third, we calculate the degree of "activeness" specifically in proximate stocks to check whether funds underweight these stocks because they have an information edge on firms with negative prospects.

\subsection{Fund Investment}

We examine fund investment before and during lockdown in the following regression:

Weight $_{\text {imt }}=\alpha+\beta *$ Lockdown $_{m t}+\gamma * D_{i m} *$ Lockdown $_{m t}+\delta * D_{i m}+$ Control $_{i t-1}+\alpha^{F E}+\varepsilon_{i m t}$. 
The dependent variable is either the portfolio weight placed on stock $i$ by fund $m$ in month $t$ or the excess weight subtracting the benchmark index's weight on the same stock. $D_{i m}$ is the distance in thousands of miles between the headquarters of fund m's management company and stock $i$ 's issuing firm. ${ }^{14}$ We consider two proxies for lockdown: the dummy variable Lockdown $_{m t}$ indicating executive orders by governments and the dummy variable Footprint $_{m t}$ indicating the contraction in real business activities. These two dummy variables capture the time-varying economic conditions in the zip code hosing fund $m$.

To control for the firm-related factors driving portfolio allocation, we use the firm fixed effect and time-varying firm characteristics such as the log of total assets $(S I Z E)$ and the return on assets $(R O A)$ using the values from the previous quarter relative to month $t$. We also control for the one-month lagged stock return $\left(R E T_{i, t-1}\right)$ to address the concern that portfolio allocation is due to a stock's performance change. Lastly, we consider controlling for the lockdown situation in the zip code where firm $i$ is located, Firm Lockdown $n_{i t}$ and Firm Footprint ${ }_{i t}$ which are defined in the same way as their counterparts, Lockdown ${ }_{m t}$ and Footprint ${ }_{m t}$, except replacing the zip codes of funds with those of firms. The firm-level lockdown variables capture the time-varying economic conditions in the zip code where firm $i$ is located.

To control for the asymmetric impact of the pandemic on industries that potentially influences portfolio allocations, we use the two-way industry $\times$ time fixed effect. The pandemic severely affected some industries such as retails and transportation, but benefited others such as those that rely on technologies, for example, Amazon and Target, or businesses catering to demand driven by the pandemic such as Home Depot, Lululemon, and Peloton (home fitness). The industry $\times$ time fixed effect absorbs the portfolio allocation driven by the timevarying industry change. We also use the fund fixed effect to control for fund-specific factors that affect the fund's portfolio allocation. Standard errors are clustered at the fund level.

\footnotetext{
${ }^{14}$ As a robustness check, we also conduct a similar experiment but replace the continuous distance $D_{i m}$ with a dummy variable $L O C A L_{i m}$ that identifies local stocks for each fund. The results are presented in Section 8 .
} 
The parameter of interest is the estimated coefficient for the interaction term, $D \times$ Lockdown. The regression results in Table 6 show a positive and statistically significant coefficient for this interaction term, indicating that funds trim down investment in proximate firms' stocks during lockdown. Robust across all four specifications, we observe that lockdown increases the investment in distant stocks. This is the case whether we consider the fund's direct investment, as proxied by fund portfolio weight (Columns (1)-(4)) or the fund's excess investment, as proxied by the excess weight with respect to the benchmark index (Columns (5)-(8)). Economically, if a firm's distance to its holding fund is one standard deviation lower than the cross-sectional average fund-firm distance (note that the fund-firm distance $D_{i m}$ is a constant in our short sample period), we will observe a $0.83 \%$ decrease in the fund's portfolio weight on the specific stock (using Specification (4)) and a $0.35 \%$ decrease in the excess weight deviated from the benchmark index (using Specification (8)). That is, if a stock's issuing firm is 100 miles closer to a holding fund than the average, funds on average will reduce the portfolio weight (the excess weight) on this stock by $0.10 \%(0.04 \%)$ during lockdown.

When using the footprint dummy as the indicator for economic contraction in Panel B, the results are similar: a one-standard-deviation decrease in the fund-firm distance crosssectionally is associated with a $0.67 \%(0.26 \%)$ decrease in the fund's portfolio weight (excess weight) on the specific stock, using Specifications (4) and (8), respectively. Note that the estimated coefficients on other explanatory variables are consistent with expectations. For example, fund managers tend to increase both fund holding weight and the excess weight when a firm has higher lagged returns, a larger size, and a higher return on assets. The positive coefficient on the Firm Lockdown or Firm Footprint dummy is not meaningful; it is positive due to the strong correlation with the fund-level lockdown variables, Lockdown $n_{m t}$

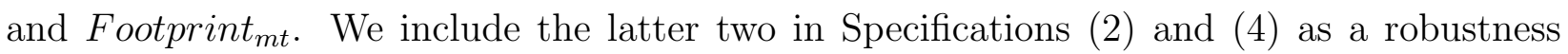
check.

The timing of portfolio rebalancing coincides with the implementation of lockdown. Fig- 
ure 4 plots the point estimates and the $95 \%$ confidence interval of the interaction coefficients $\left(\gamma_{s}\right)$ from a modified version of Specification (8) in Panel A of Table 6:

$$
\begin{aligned}
\text { ExWeight }_{i m t}= & \alpha+\sum_{s=t-3}^{t+3}\left(\beta_{s} * \text { Event }_{m s}+\gamma_{s} * D_{i m} \times \text { Event }_{m s}\right) \\
& +\delta * D_{i m}+\text { Control }_{i, t-1}+\alpha^{F E}+\varepsilon_{i m t} .
\end{aligned}
$$

Event $_{m s}$ is a dummy variable indicating months relative to the fund-specific lockdown shock. The figure indicates no statistical difference in a fund's excess investment prior to the lockdown shock, with the estimated coefficients of $0.0023(s=t-3), 0.0030(s=t-2)$, and 0.0041 $(s=t-1)$, with $p$-values of $0.36,0.24$, and 0.17 , respectively. That is, proximate stocks,

on average, do not seem to have more or less excess investment relative to distant stocks for all funds in our sample before their holding funds' areas initiate lockdown. However, investment in distant stocks tends to grow thereafter. This growth begins in the same month as lockdown is imposed in the holding fund's zip code and continues for approximately three months during lockdown, with the gamma estimates of $0.0069(s=t), 0.0096(s=t+1)$, $0.0083(s=t+2)$, and $0.0041(s=t+3)$, and the $p$-values ranging from 0.001 to 0.10 . The precise timing of the growth suggests that it is caused by the lockdown shock rather than by any omitted firm, fund, or industry characteristics. The timing of this growth also confirms the quality of our identification.

\subsection{A Snapshot of the Firm-Fund Distance Change}

We now take a snapshot of the firm-fund distance for firms newly invested in during lockdown, firms divested from the pre-pandemic portfolio, and firms with an increase or decrease in investment from the normal to the lockdown time. We examine these situations for funds in five portfolios sorted by their pre-pandemic average holding distance as of March 2019 based on the excess holding weight from each fund's benchmark index.

To facilitate the comparison, we calculate the percentage difference in the average distance 
between the firms newly invested in and the firms divested from during lockdown for each fund. The blue bars in Figure 5 show the mean value of this percentage difference for funds in each investment-distance-sorted portfolio. We also calculate the percentage difference in the average distance between existing firms with increasing investment and those with decreasing investment during lockdown. The mean values of these differences are illustrated in pink bars in Figure 5.

Under both measures, we observe a consistent pattern that funds in all five investmentdistance-sorted portfolios trim down investment in proximate stocks while increasing investment in distant stocks. However, funds investing locally before the pandemic, that is, those in Portfolio $A D \_1$, have a significantly higher change than funds in other portfolios. For the local-investing funds, the average distance to the newly invested firms is $12.87 \%$ farther than the distance to the firms divested from during lockdown. In contrast, for farther investing funds (i.e., funds in Portfolios $A D \_2$ to $A D \_5$ ), the average distance to the newly invested firms is between $2.63 \%$ and $7.38 \%$ farther than the distance to the firms divested from during lockdown. The contrast is even greater when comparing the distance to the stocks of firms invested in both before and during the pandemic. For the local-investing funds, the average distance to the firms in which they increased investment in during lockdown is $24.08 \%$ farther than the firms in which they reduced investment. This number is between $6.73 \%$ and $9.34 \%$ for funds in Portfolios $A D \_2$ to $A D \_5$.

This snapshot confirms that funds with a preference for proximity investment tend to rebalance the portfolios toward distant stocks when they lose their information edge during lockdown.

\subsection{Activeness in Proximate Stocks}

The decrease in portfolio weights in proximate stocks does not necessarily suggest the loss of local information edge since better local information may also translate into shorting or underweighting stocks in the presence of negative information. While mutual funds cannot 
short, we can still test whether they explore such negative information by examining a fund's activeness in proximate stocks.

To investigate the activeness in proximate stocks, we depart from the conventional activeness measure in Cremers et al. (2016) that uses all the stocks a fund should invest in. Instead, we estimate the degree of the fund's activeness in its local stocks as the average absolute deviation between the percentage investment in local stocks of the fund and the percentage investment by the fund's benchmark index. For each fund, we categorize the stocks in its holdings as local stocks if their issuing firms are within 250 miles of the fund's management company, following the same approach as in Section 4.5. Table 7 shows that the local-investing funds significantly reduce their activeness in local stocks during lockdown. For example, the combined coefficient on Footprint and Footprint $\times$ LIFD is negative, -0.74 with a $p$-value of 0.09 using the Wald test. ${ }^{15}$ The combined coefficient on Lockdown and Lockdown $\times L I F D$ is negative but not statistically significant. Thus, our results document that shifting away from proximate stocks is not related to actively exploiting negative information during lockdown; rather, it is due to the loss of physical human-interaction-based information edge. The portfolio rebalances also indicate that the seemingly natural substitute of virtual meetings via Zoom/Skype/Teams cannot provide the same information to compensate for that originating from physical contacts.

\section{From Active Performance Seeking to Passive Risk Management}

The previous two sections show that mutual funds that invested locally before the pandemic tend to trim down investment in proximate stocks and rebalance their portfolios toward distant stocks during lockdown. This portfolio adjustment leads to deteriorating performance for the local-investing funds that exceeds the average performance decline during lockdown. These findings suggest that the lockdown-triggered social isolation significantly

\footnotetext{
${ }^{15}$ The net effect of the local-investing funds' activeness in proximate stocks is the combination of the coefficients on the lockdown dummy and the interaction term of lockdown with the local-investing fund dummy.
} 
hindered the collection, processing, and transmission of physical human-interaction-based soft information. In this section, we continue to examine how mutual funds react to the loss of human-interaction-based information in terms of risk management.

\subsection{Reliance on Public Information}

We first examine the characteristics of the stocks that funds buy and sell during lockdown. Panel A of Table 8 shows that the local-investing funds shift their portfolios toward stocks that have more "tangible" information. The stocks that they buy during lockdown tend to have a smaller dispersion of analyst forecasts and smaller forecast errors than the stocks that they sell. For both measures, the $p$-value is less than 10\%, 0.0808 for the dispersion of analyst forecasts and 0.0042 for forecast error. In contrast, the distant-investing funds did not significantly adjust their portfolios toward stocks with more tangible information with both $p$-values being larger than $10 \%$.

We also construct a measure of reliance on public information, $R P I$, using a similar method to that developed by Kacperczyk and Seru (2007). RPI estimates how much of the average percentage changes in a fund's holdings can be attributed to the changes in analysts' consensus recommendations. Specifically, for each fund $m$ during quarter $t$ from 2019 Q1 to 2020Q2, we estimate the following cross-sectional regression using all stocks in each fund's portfolio:

$$
\% \Delta \text { Holding }_{\text {imt }}=\beta_{0, t}+\beta_{1, t} \Delta \operatorname{Rec}_{i, t-1}+\varepsilon_{i m t}, \quad \forall m
$$

where $\% \Delta$ Holding $_{\text {imt }}$ denotes the percentage change in the holdings of stock $i$ held by fund $m$ during quarter $t . \Delta R e c_{i, t-1}$ measures the change in the recommendation of the consensus forecast for stock $i$ during quarter $t-1$, which we download from IBES' Consensus Recommendations data ${ }^{16}$ The measure of RPI equals the unadjusted $R^{2}$ of regression (12).

We separately test the difference in RPI before and during lockdown for the local-investing

\footnotetext{
${ }^{16}$ We classify an observation as missing if we do not observe a forecast for any quarter required in the specification. Since adding a new stock position into a fund portfolio would imply an infinite increase in the holdings of the stock, in such cases we set $\% \Delta$ Holding $_{i m t}$ to $100 \%$.
} 
and the distant-investing funds. Panel B in Table 8 presents the $t$-test results. We find that funds that invested locally significantly increase their RPI during lockdown: RPI increased from 0.0182 to 0.0245 with a $p$-value of 0.0388 for the hypothesis of the difference being larger than zero. Funds investing far away did not experience a statistically significant change in RPI.

These findings on fund investment suggest that after losing the human-interaction-based information edge, the local-investing funds attempt to use more non-interaction-based information. In contrast, given that the pandemic lockdown did not significantly affect the information technology for the distant-investing funds, the latter have no motivation to change their investments. However, the combined evidence on fund investment and performance indicates that the switching from human-based to non-human-based information is not successful. Ultimately, hard information was not the revealed preference for the local-investing funds before the pandemic. It takes time and money to switch to the new, non-interactionbased information technology.

\subsection{Fund Risk Management}

Does the failure of effectively replacing physical human-interaction-based information with virtual-interaction-based or non-interaction-based information induce mutual fund managers to take precautionary measures? We expect that such ineffective information substitution will lead to less willingness by fund managers to take risks.

We first examine the impact of lockdown on the risk exposure of the local-investing funds through fund portfolio concentration:

$$
H H I_{m t}=\alpha+\beta * \text { Lockdown }_{m t}+\gamma * \text { Lockdown }_{m t} \times L I F D_{m}+\alpha_{m}+\alpha_{t}+\varepsilon_{m t} .
$$

$H H I_{m t}$ is fund $m$ 's Herfindahl-Hirschman Index in month $t$, which is the sum of squared holding weights. $L I F D_{m}$ is an indicator variable for the local-investing funds, which is equal 
to one if a fund invests more in local stocks (Portfolio $A D \_1$ ) before the pandemic and zero if a fund invests more in distant stocks (Portfolio $A D_{-} 5$ ). We control for the fund and time (year-month) fixed effects. Note that the fund fixed effect absorbs the local-investing-fund dummy. Standard errors are clustered at the fund family level.

Table 9 shows that funds that invested locally before the pandemic tend to reduce the concentration of their portfolio holdings during lockdown, whereas funds investing far away seem to maintain their portfolio concentration. The results are robust to both using the executive order imposing lockdown and the inferring lockdown from real business contraction. In addition, the results are robust to calculating the concentration with all portfolio holdings and with only top ten largest holdings. Using the concentration measure based on the top ten largest holdings as an example, we see that the coefficient on the interaction term is $-0.2087(t$-stat $=-3.95)$ when lockdown is measured by executive orders and is $-0.2009(t-$ stat $=-3.83$ ) when lockdown is measured by footprint contraction. Given that the mean value of concentration in this test sample is 1.8509 , the portfolio concentration of the localinvesting funds declines by approximately $11 \%$ of the mean value during lockdown compared to that of the distant-investing funds.

Next, we examine the risk management of mutual funds through their risk-shifting behavior. Inspired by Huang, Sialm, and Zhang (2011), we measure the risk-shifting of a mutual fund $m$ at time $t$ by comparing a hypothetical portfolio's volatility based on the fund's previously disclosed holdings $\left(\sigma_{m, t}^{H}\right)$ with the past realized volatility based on the fund's returns $\left(\sigma_{m, t}^{R}\right)$ :

$$
R S_{m, t}=\sigma_{m, t}^{H}-\sigma_{m, t}^{R} .
$$

Here, the hypothetical portfolio is constructed in the same way as in the return gap in Section 4.3, except using daily firm returns. The hypothetical portfolio's volatility $\sigma_{m, t}^{H}$ is estimated using the standard deviation of the hypothetical portfolio's daily returns in month $t$ based on the previously disclosed fund holdings at the beginning of the month. The past realized volatility $\sigma_{m, t}^{R}$ is estimated using the sample standard deviation of the fund's daily 
actual returns within month $t$. A positive value of $R S$ indicates that a fund takes action to reduce risks.

In Figure 6, we report the point estimates that capture the effect of funds' proximity investment preference on their risk shifting from three months before the lockdown shock through three months thereafter. We also report the $95 \%$ confidence intervals, adjusted for clustering at the fund family level. The figure suggests no difference in risk-shifting behavior between the local-investing and the distant-investing funds before lockdown, with estimated coefficients of $-0.0067(s=t-3),-0.0055(s=t-2)$, and $-0.0301(s=t-1)$, and $p$ values of $0.44,0.53$, and 0.27 , respectively. However, as the lockdown shock hits the market, the local-investing funds take action to reduce risks. The risk-reduction action lasts for two months with gamma estimates of $0.0925(s=t)$ and $0.0687(s=t+1)$, both with a $p$-value smaller than 0.10. Then, there is no significant difference in risk-shifting behavior between the local-investing and the distant-investing funds.

The results in this subsection confirm the intuition that the local-investing funds, being unable to regain their informational edge in the short run, compensate by reducing portfolio concentration and taking less risk.

\section{$7 \quad$ Is There a Human Touch?}

We now investigate the nature of human-interaction-based information. We have described this information as originating from people interacting with each other. The question is whether this is the case and where most interactions occur. To answer this question, we investigate the channel of the lockdown impact by examining footprint activities in each industry and the different impacts of their contractions on fund performance during lockdown:

$$
\text { ExRet }_{m t}=\alpha+\beta * \text { Activity }_{m t}^{k}+\gamma * A D_{m}^{M a r 2019} \times \text { Activity }_{m t}^{k}+\alpha_{m}+\alpha_{t}+\varepsilon_{m t} .
$$


$A_{c t i v i t y}^{k}$ is the log of the number of visits to a specific group of brands in the fund $m$-located zip code in month $t$ and then is multiplied by -1 . Multiplying by -1 makes the interpretation of the variable consistent with two other proxies of lockdown in previous tables. Activity indeed measures the contraction of foot print activities; the less foot traffic activities there are in a zip code, the larger the variable "Activity" is.

We report the results in Panel A of Table 10. Following Williams (2020), we classify all points of interest into 13 industries based on the first two digits of the NAICS codes. For example, if the first two digits of the NAICS code start with 72 , we consider it accommodation and food services. We consider the following activities: accommodation \& food, entertainment \& recreation, educational services, other types of services, financial and insurance business, real estate, health care, information services, manufacturing, retail trade, transport \& warehousing, wholesale trade, and public administration. Under this broad categorization, Panel A shows that the contraction of activities in most businesses leads to a performance differentiation for the local-investing and the distant-investing funds, supported by a significant and positive estimated coefficient on the interaction term.

We also run a horse race and include these industries in a single regression. Panel B shows that only two industries continue to have a significant impact: arts, entertainment \& recreation (NAICS code 71) and accommodation and food Services (NAICS code 72). ${ }^{17}$

Inspired by the horse race results, we refine the categorization by the four digits of NAICS codes within the general service category. It includes drinking places (alcoholic beverages), personal care services, amusement parks and arcades, etc. We also combined cafeterias, limited-service restaurants and snack and nonalcoholic beverage bars as one category, and combined bowling centers and golf courses and country clubs as one category. Panel C shows that among the subcategories, the impact of amusement parks, bowling and golf, child care,

\footnotetext{
${ }^{17}$ Not every zip code has all types of industrial activities. The horse race regression will remove zip codes from the sample with only partial coverage in industry groups. To alleviate the concern that many such zip codes will be removed from the regression, we first filter out several industries with a low number of observations in the sample, say fewer than 10,000 observations. Based on this criterion and the numbers of observations in Panel A, five industries are removed from the horse race regression. They are manufacturing, wholesale trade, educational services, public administration (PA), and other service except for PA.
} 
or personal care is not significant. In contrast, the impact of cafés \& bars, full-service restaurants, drinking places, fitness \& sports centers, and bookstores is salient.

These results indicate a channel of human interactions that revolves around meeting places such as cafés, restaurants, bars, and fitness centers where people, i.e., fund managers and corporate affiliates such as firm managers and employees, meet and exchange information and perspectives. This finding provides evidence in favor of a "human touch" channel as posited by the physical human interaction hypothesis (H1).

Our results also have important normative and regulatory implications because they provide clear evidence that proximity investment is not linked to information about the local economy but rather the people managing the local firms. Any exogenous shock to using such information curtails the ability to deliver performance. These findings suggest that a "new world" based on Zoom/Skype/Teams and remote connection cannot generate sufficient information to substitute for the information originating from physical contacts. In short, no alternative channels can replace the "human touch."

\section{Robustness Check}

\subsection{Mutual Funds with Sub-Advisors}

In the main analysis, a fund's investment distance $A D$ is calculated between the headquarter of a fund's management company and those of its holding firms. However, a fund may not be managed directly by its family; rather it can subcontract out its management. In that case, the investment distance is measured with bias. Given the difficulty of identifying the location of funds' sub-advisors, we address the concern of a biased measure by comparing the impact of lockdown on fund performance for funds with and without sub-advisors. Specifically, we run the following regression: 


$$
\begin{aligned}
\text { Ret }_{m t}= & \alpha+\beta * \text { Lockdown }_{m t}+\zeta * \text { AD }_{m}^{\text {Mar2019 }} \times \text { Lockdown }_{m t} \times \text { SubAdvisor } \\
& +\gamma * A D_{m}^{\text {Mar2019 }} \times \text { Lockdown }_{m t}+\delta * \text { Lockdown } \times \text { SubAdvisor }+Z_{m}+Z_{t}+(16) .
\end{aligned}
$$

SubAdvisor is a dummy variable that equals to one if a fund subcontracts out its management to one or a few sub-advisors.

Table 11 reports the results. The coefficient on the triple interaction, $\zeta$, is statistically insignificant. Moreover, the coefficient of the interaction between Lockdown and SubAdvisor, $\delta$, is insignificant. These estimates jointly indicate that the performance of funds with and without sub-advisors is indistinguishable during lockdown. Moreover, the use of sub-advisors in management does not affect the performance of funds with different pre-pandemic geographical preferences during lockdown. The negligible influence of using sub-advisors alleviates the concern that the potentially biased measure of investment distance can distort the main findings. It also suggests that the main results would not be substantially different even if we could accurately measure the investment distance using the locations of sub-advisors.

\subsection{Robustness Check for Fund Investment}

One primary finding is that funds that invested locally before the pandemic tend to reduce investments in local stocks and rebalance their portfolio toward distant stocks. The supporting evidence is provided by Table 6 where we adopt the continuous measure of the distance between a fund and a given holding firm. In this subsection, we conduct a robustness check by replacing the continuous distance $D_{i m}$ with a dummy variable $L O C A L_{i m}$, which is equal to one if a firm is within 250 miles of the holding fund's headquarter and zero if it is more than 1250 miles away from the holding fund.

Table 12 presents the results. The estimated coefficient of Lockdown $n_{m t}$ is positive but statistically insignificant, indicating that on average, the excess investment weight on all firms 
during lockdown does not significantly differ from that before. However, the negative and significant estimates for the interaction term $L O C A L * L o c k d o w n_{m t}$ in various specifications suggest that mutual funds significantly reduce investment in local stocks during lockdown. Economically, the reduction in investment in local stocks is sizable. On average, the excess investment weight on local stocks decreased approximately $1.07 \sim 1.29 \%$ during lockdown, which doubles the mean value of excess investment weight, $0.56 \%$.

\section{Conclusion}

In this paper, we study the substitutability of various types of information, the intangible and qualitative information collected through human interactions and the intangible, quantifiable, and codifiable information collected through non-human interactions. We further examine whether human-interaction-based information is tied to physical contacts or virtual meetings are sufficient to produce it.

The COVID-19 pandemic-triggered lockdown provides a natural randomized experiment to test information substitutability. Lockdown restrains physical contacts and hence exogenously hinders human-interaction-based information collection. In contrast, lockdown exerts little influence on other information technologies, for example, information garnered through electronic filings, financial and accounting data collected in hard or electronic format, and machine learning. Moreover, lockdown was imposed at different times and with different intensities across zip codes. Thus we can utilize the cross-sectional and time-series variation of lockdown to test their differential impact on proximity investment, of which human-interaction-based information is argued to be one of the main drivers.

We find that all funds perform poorly during lockdown. However, funds investing locally before the pandemic perform worse during lockdown than funds investing far away. In addition, the two types of funds did not have significantly different performance before lockdown. That is, fund investment distance does not affect fund performance in normal times. 
These findings jointly suggest that proximity investment relates to the ability to collect and process soft information accrued through physical human interactions and that lockdown induces a reduction in physical contacts and hence a loss of an information advantage for the local-investing funds. As a result, funds with a geographical preference for proximate stocks perform worse during lockdown than funds investing distantly.

We also find that funds investing locally before the pandemic markedly reduced their investment in proximate stocks and shifted their portfolios toward distant stocks during lockdown. Such portfolio rebalancing is not due to funds exploiting the information edge of local firms with negative prospects and therefore underweighting the related stocks. Moreover, the stocks newly invested in during lockdown have less analyst forecast dispersion and smaller forecast errors than the divested stocks, suggesting an effort by fund managers to seek more tangible information after the loss of local information edge. The combined findings on fund performance and investment indicate that virtual human interactions cannot produce sufficient information to substitute for information collected from physical interactions. Additionally, human-interaction-based information cannot easily be replaced by non-humaninteraction-based information.

Overall, this paper emphasizes that in the new machine age, human interaction remains an important channel to collect and process information. Setting technology to one side, the human dimension will always prevail, purely because we understand more when a person connects, delivers, interacts, and raises a point of view. As evidenced during the COVID-19 pandemic, physical human interaction is essential not only to emotional and physical health, ${ }^{18}$ but also to information collection and transmission.

\footnotetext{
${ }^{18}$ Numerous cases and studies show that social isolation is linked to serious health conditions during lockdown. For example, according to a report from the National Academies of Sciences, Engineering, and Medicine, social isolation has been linked to a 50 percent increased risk of dementia, a 29 percent increased risk of heart disease, and a 32 percent increased risk of stroke. (Source: https://www.nap.edu/catalog/ 25663/social-isolation-and-loneliness-in-older-adults-opportunities-for-the)
} 


\section{References}

Aghion, Philippe, and Jean Tirole, 1997, Formal and real authority in organizations, Journal of Political Economy 105, 1-29.

Bae, Kee-Hong, René Stulz, and Hongping Tan, 2008, Do local analysts know more? a cross-country study of the performance of local analysts and foreign analysts, Journal of Financial Economics $88,581-606$.

Baik, Bok, Jun-Koo Kang, and Jin-Mo Kim, 2010, Local institutional investors, information asymmetries, and equity returns, Journal of Financial Economics 97, 81-106.

Begenaua, Juliane, Maryam Farboodi, and Laura Veldkamp, 2018, Big data in finance and the growth of large firms, Journal of Monetary Economics 97, 71-87.

Berger, Allen N., Nathan Miller, Mitchell A. Petersen, Raghuram H. Rajan, and Jeremy C. Stein, 2005, Does function follow organizational form? evidence from the lending practices of large and small banks, Journal of Financial Economics 76, 237-269.

Berk, Jonathan B., and Richard C. Green, 2004, Mutual fund flows and performance in rational markets, Journal of Political Economy 112, 1265-1295.

Bernille, Gennaro, Alok Kumar, and John Sulaemen, 2015, Home away from home: Geography of information and local investors, Review of Financial Studies 28, 2009-2049.

Bernstein, Shai, Xavier Giroud, and Richard Townsend, 2015, The impact of venture capital monitoring, Journal of Finance 71, 1591-1622.

Brennan, Michael J., and H. Henry Cao, 1997, International portfolio investment flows, Journal of Finance 52, 1851-1880.

Brogaard, Jonathan, Matthew Ringgenberg, and Dominik Roesch, 2021, Does floor trading matter?, Working Paper, University of Utah.

Butler, Alexander W., 2008, Distance still matters: Evidence from municipal bond underwriting, Review of Financial Studies 21, 763-784.

Choe, Hyuk, Bong-Chan Kho, and René M. Stulz, 2005, Do domestic investors have an edge? the trading experience of foreign investors in korea, Review of Financial Studies 18, 795-829.

Coval, Joshua D., and Tobias J. Moskowitz, 1999, Home bias at home: Local equity preference in domestic portfolios, Journal of Finance 54, 2045-73.

Coval, Joshua D., and Tobias J. Moskowitz, 2001, The geography of investment: Informed trading and asset prices, Journal of Political Economy 109, 811-41.

Cremers, Martijn, Miguel A. Ferreira, Pedro Matos, and Laura Starks, 2016, Indexing and active fund management: International evidence, Journal of Financial Economics 120, 539-560.

Da, Zhi, Umit G. Gurun, Bin Li, and Mitch Warachka, 2021, Investment in a smaller world: the implications of air travel for investors and firms, Management Science forthcoming. 
Elton, Edwin J., Martin J. Gruber, and Christopher R. Blake, 2001, A first look at the accuracy of the crsp mutual fund database and a comparison of the crsp and morningstar mutual fund databases, Journal of Finance 56, 2415-2430.

Fama, Eugene F, and Kenneth R French, 2015, A five-factor asset pricing model, Journal of Financial Economics 116, 1-22.

Gaspar, Jose-Miguel, and Massimo Massa, 2007, Local ownership as private information: Evidence on the monitoring-liquidity trade-off, Journal of Financial Economics 83, 751-92.

Giannetti, Mariassunta, and Luc Laeven, 2016, Local ownership, crises, and asset prices: Evidence from us mutual funds, Review of Finance 947-978.

Grennan, Jillian, and Roni Michaely, 2020, Fintechs and the market for financial analysis, Journal of Financial and Quantitative Analysis 56, 1877-1907.

Han, Bing, David Hirshleifer, and Johan Walden, 2021, Social transmission bias and investor behavior, Journal of Financial and Quantitative Analysis forthcoming.

Hau, Harald, 2001, Location matters: An examination of trading profits, Journal of Finance 56, 1959-1983.

Hong, Harrison, Jeffrey D. Kubik, and Jeremy C. Stein, 2005, Thy neighbor's portfolio: Word-ofmouth effects in the holdings and trades of money managers, Journal of Finance 60, 2801-24.

Huang, Jennifer, Clemens Sialm, and Hanjiang Zhang, 2011, Risk shifting and mutual fund performance, Review of Financial Studies 24, 2575-2616.

Huberman, Gur, 2001, Familiarity breeds investment, Review of Financial Studies 14(3), 659-80.

Jagannathan, Murali, Wei Jiao, and G. Andrew Karolyi, 2018, Is there a home field advantage in global markets?, Mutual Funds .

Kacperczyk, Marcin, and Amit Seru, 2007, Fund manager use of public information: New evidence on managerial skills, Journal of Finance 62, 485-528.

Kacperczyk, Marcin T., Clemens Sialm, and Lu Zheng, 2008, Unobserved actions of mutual funds, Review of Financial Studies 21, 2379-2416.

Korniotis, George M., and Alok Kumar, 2012, State-level business cycles and local return predictability, Journal of Finance 68(3), 1037-1096.

Lai, Sandy, and Melvyn Teo, 2008, Home-biased analysts in emerging markets., Journal of Financial and Quantitative Analysis 43, 685-716.

Liberti, Jose, and Atif Mian, 2009, Estimating the effect of hierarchies on information use, Review of Financial Studies 22, 4057-4090.

Liberti, José M., and Mitchell A. Petersen, 2019, Information: Hard and soft, Review of Corporate Finance Studies 8(1), 1-41.

Malloy, Christopher J., 2005, The geography of equity analysis, Journal of Finance 60, 719-755. 
Mehrabian, Albert, 1972, Nonverbal communication, Chicago : Aldine-Atherton .

Mehrabian, Albert, 1981, Silent messages: implicit communication of emotions and attitudes, Belmont, Calif. : Wadsworth Pub. Co. .

Obstfeld, Maurice, and Kenneth Rogoff, 2000, The six major puzzles in international macroeconomics: Is there a common cause?, NBER Macroeconomics Annual 200015.

Petersen, Mitchell A., 2004, Information: Hard and soft, Working Paper, Northwestern University.

Pool, Veronika K., Noah Stoffman, and Scott E. Yonker, 2012, No place like home: Familiarity in mutual fund manager portfolio choice, Review of Financial Studies 25, 2563-2599.

Seasholes, Mark M., and Ning Zhu, 2010, Individual investors and local bias, Journal of Finance 65, 1987-2010.

Shiller, Robert J., and J. Pound, 1989, Survey evidence on the discussion of interest and information among investors, Journal of Economic Behavior and Organization 12, 47-66.

Sialm, Clemens, Zheng Sun, and Lu Zheng, 2020, Home bias and local contagion: Evidence from funds of hedge funds, Review of Financial Studies 33, 4771-4810.

Stein, Jeremy C., 2002, Information production and capital allocation: Decentralized versus hierarchical firms. individual investors and local bias., Journal of Finance 65, 1891-1922.

Strong, Norman, and Xingzhong Xu, 2003, Understanding the equity home bias: Evidence from survey data, Review of Economic Statistics 85, 307-312.

Teo, Melvyn, 2009, The geography of hedge funds, Review of Financial Studies 22, 3531-61.

Veldkamp, Laura, and Stijn Van Nieuwerburgh, 2009, Information immobility and the home bias puzzle, Journal of Finance 64, 1187-1215.

Williams, Noah, 2020, Measuring wisconsin economic activity using foot traffic data, Working paper in the Center for Research on the Wisconsin Economy, University of Wisconsin-Madison.

Zhu, Christina, 2019, Big data as a governance mechanism, Review of Financial Studies 32, 20212061.

Ľuboš Pástor, and Blair Vorsatz, 2020, Mutual fund performance and flows during the covid-19 crisis, Review of Asset Pricing Studies 10, 791-833. 
Panel A The aggregate footprint activities

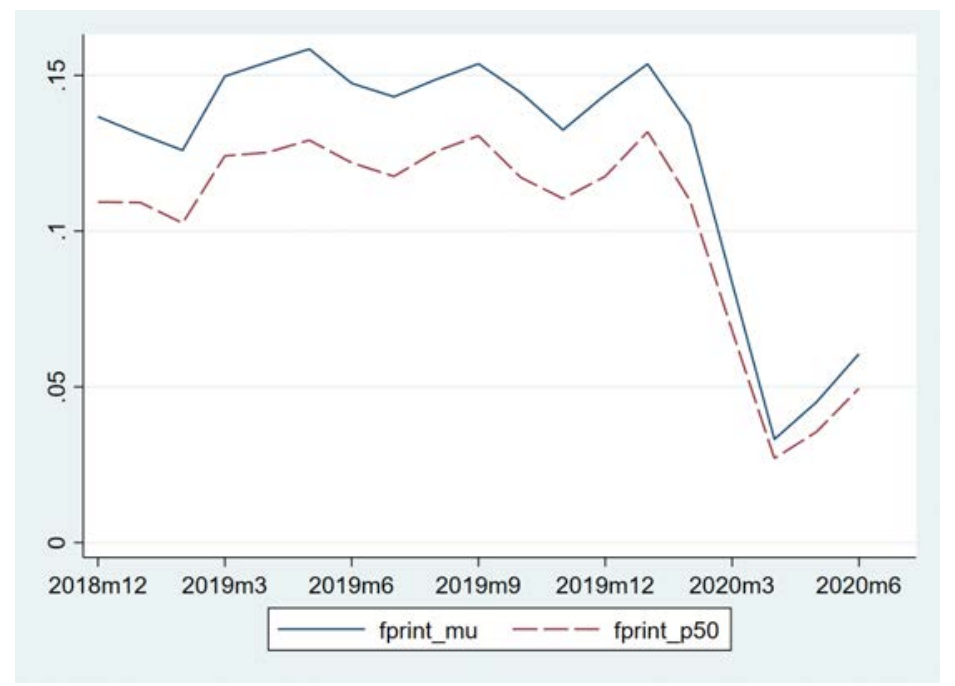

Panel B The histogram of the percentage change of footprint activities in lockdown
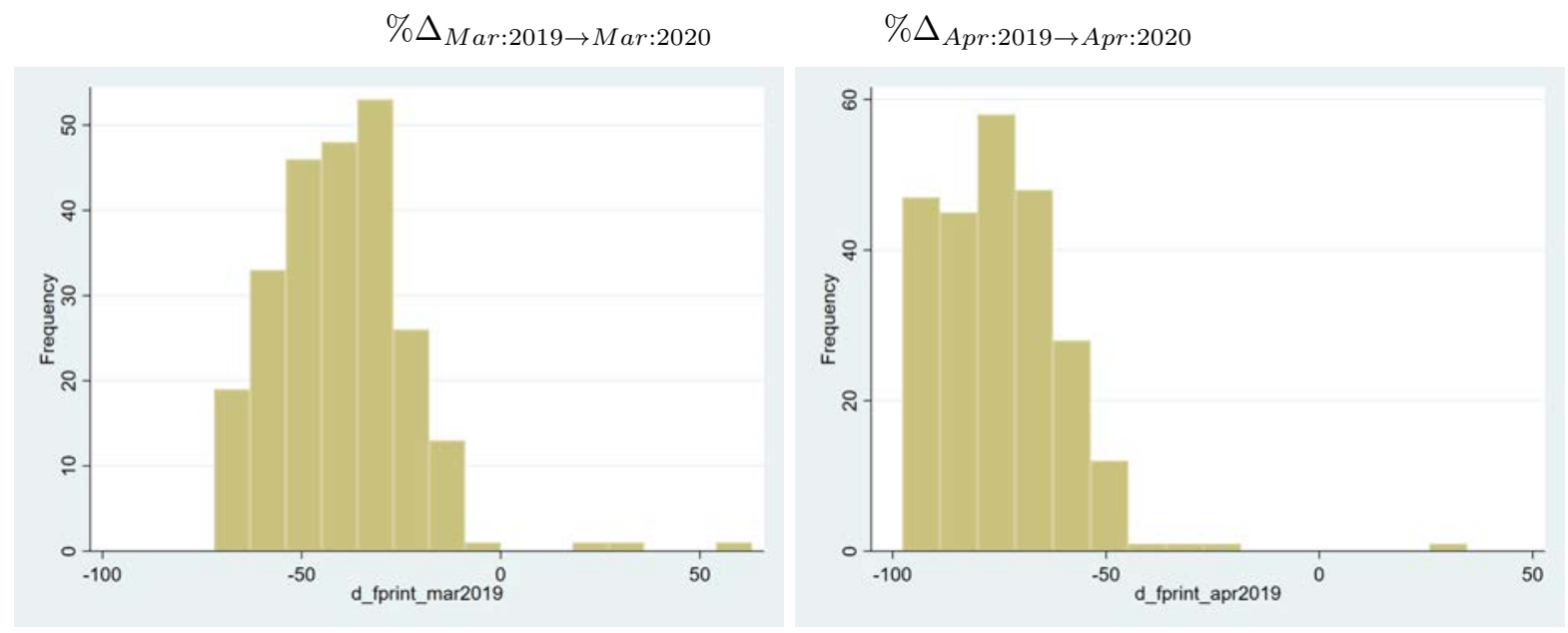

Figure 1: Footprint Activities.

Panel A shows the mean and median values of the total footprint activities (in millions) across zip codes in which mutual fund management companies are located. Panel B shows the histogram graphs of the percentage change of the total footprint activities between March (April) of 2019 and March (April) of 2020. Most states embarked lockdown in March or April of 2020. 


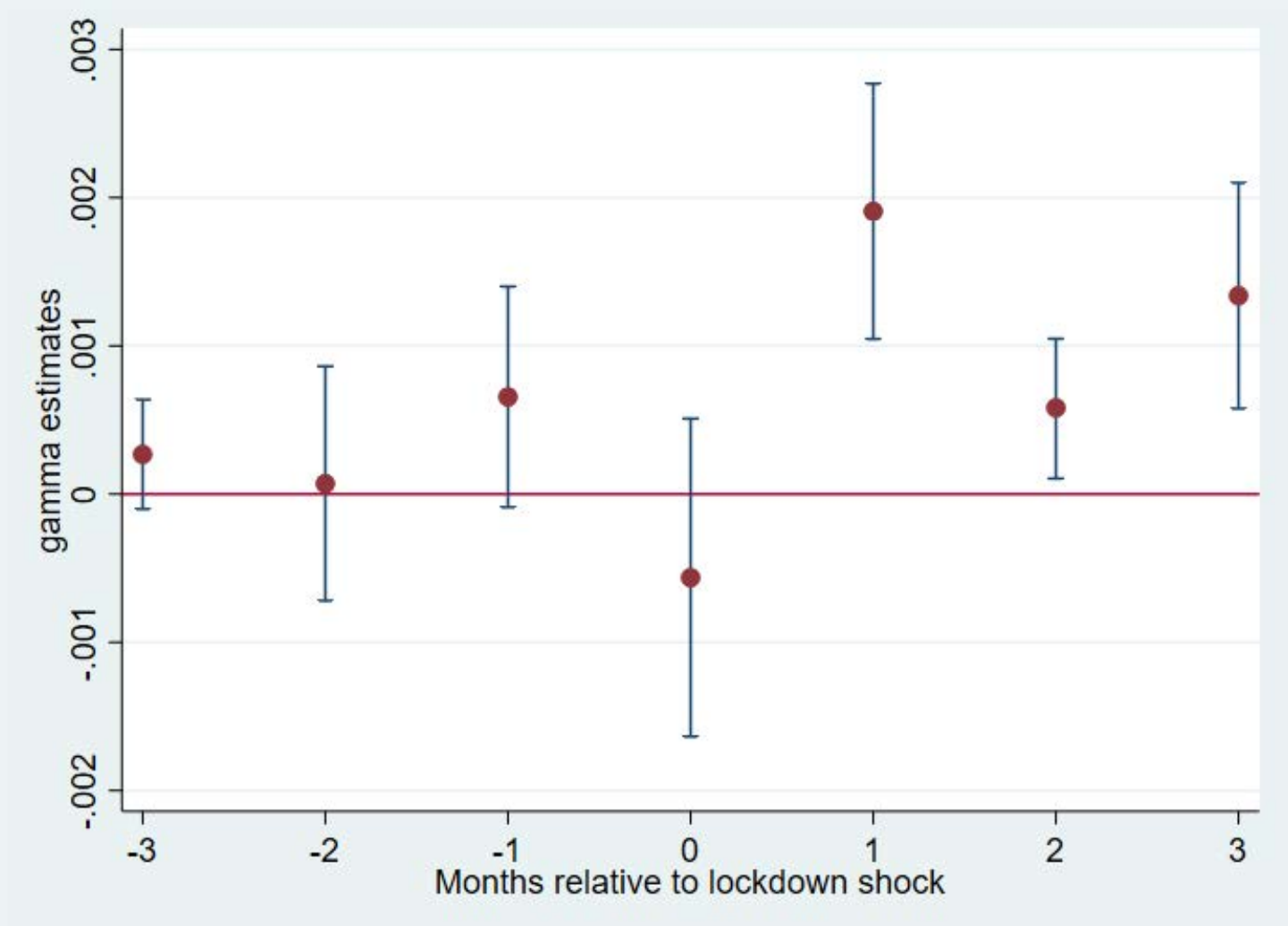

Figure 2: The Impact of Lockdown on Fund Return: Parallel Trend.

The figure plots the point estimates of the interaction coefficients, $\gamma_{s}$, in the following regression using specification (2) in Table 2:

$$
\text { ExRet }_{m t}=\alpha+\sum_{s=t-3}^{t+3}\left(\beta_{s} * \text { Event }_{m s}+\gamma_{s} * A D_{m}^{\text {Mar2019 }} \times \text { Event }_{m s}\right)+\alpha^{F E}+\varepsilon_{m t} .
$$

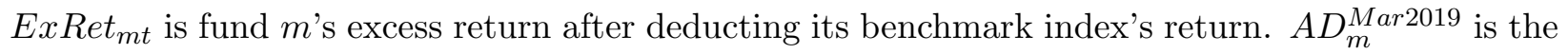
weighted average distance in miles between the headquarters of fund $m$ 's management company and all its holding stocks, using the excess weight between fund $m$ 's holdings and corresponding benchmark index's holdings in March 2019. Event Evs $_{s}$ is a dummy variable indicating the time distance to the fund-specific lockdown event. When $s=t$, it refers to the year-month when the zip code which fund $m$ is headquartered starts the executive order of lockdown. When $s=t-3$, it refers to the time point three months before the start of fund $m$-located zip code's lockdown. Ninety-five percent confidence intervals, adjusted for clustering at the fund family level, are also plotted. 


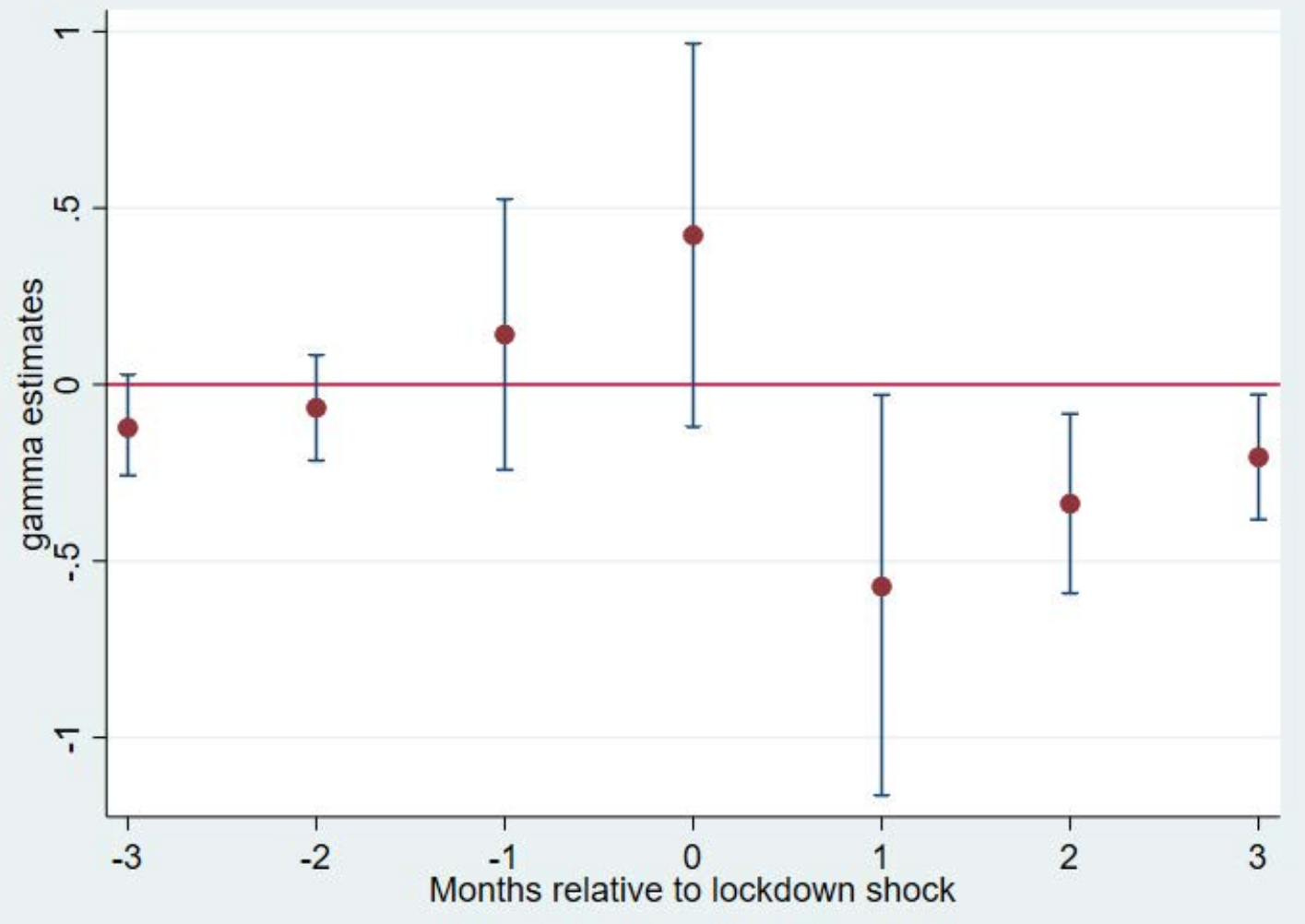

Figure 3: Return Gap

For each fund, we calculate the return gap according to Kacperczyk, Sialm, and Zheng (2008), which is defined in Equation (6) and captures the difference between the reported fund return and the return on a hypothetical portfolio that invests in the previously disclosed fund holdings. We sort funds into quintile portfolios according to their pre-pandemic weighted average distance to holding firms as of March 2019: $A D_{-} 1, \cdots, A D_{-} 5$. We report the point estimates, $\gamma_{s}$, in the following regression which captures the effect of funds' proximity investment preference on the return gap from three months before the lockdown shock through three months after:

$$
\operatorname{ReturnGap}_{m t}=\alpha+\sum_{s=t-3}^{t+3}\left(\beta_{s} * \text { Event }_{m s}+\gamma_{s} * \text { LIFD }_{m} \times \text { Event }_{m s}\right)+\alpha_{F E}+\varepsilon_{m t}
$$

$L I F D_{m}$ is a local-investing-fund dummy which is equal to one if a fund invests more in local stocks (Portfolio $A D_{-} 1$ ), and zero if a fund invests more in distant stocks (Portfolio $A D_{-} 5$ ). Ninety-five percent confidence intervals, adjusted for clustering at the fund family level, are also plotted. 


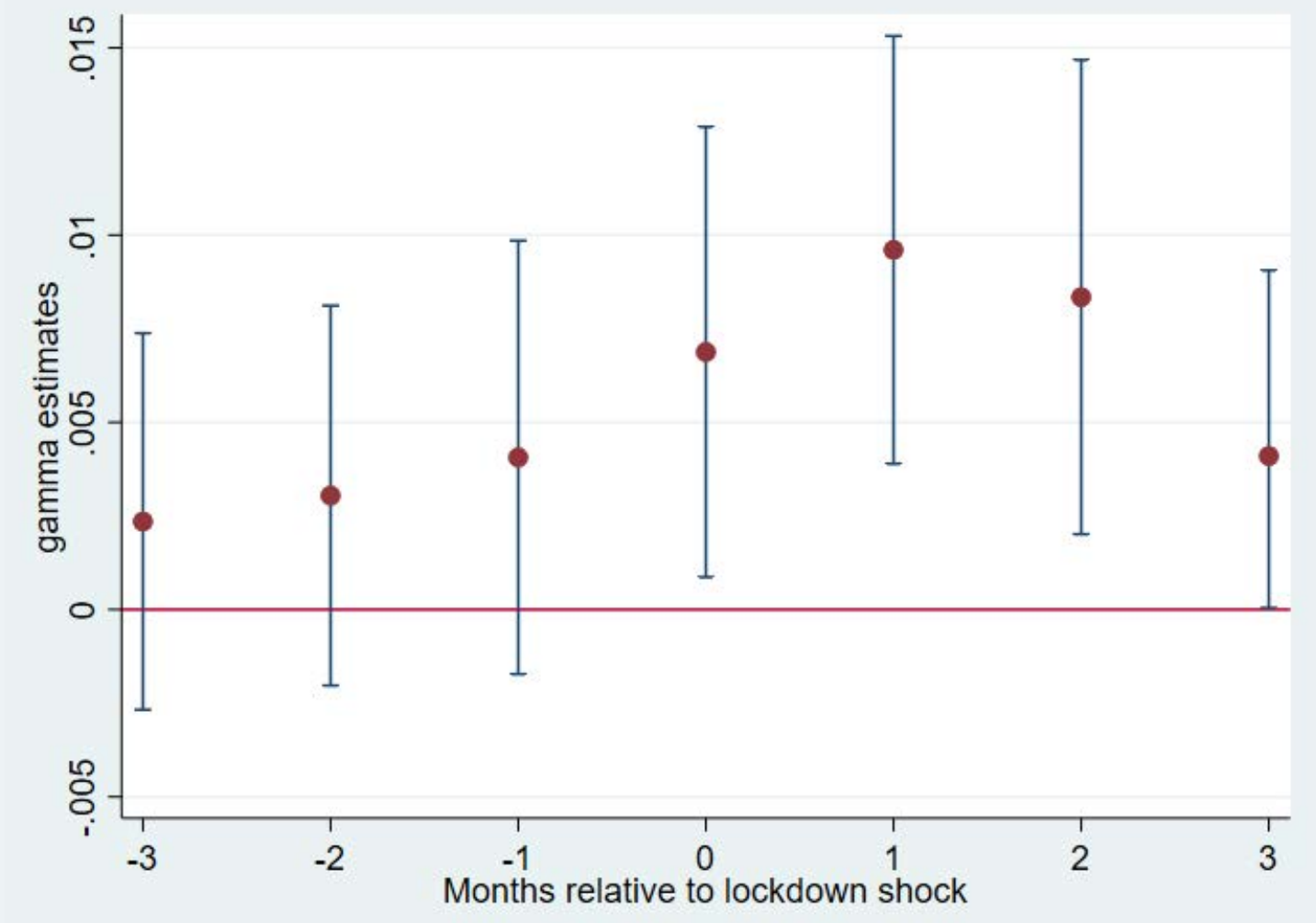

Figure 4: The Impact of Lockdown on Fund Asset Allocation: Parallel Trend. The figure depicts the parallel trend for the regression in Table 6. We plot the estimates of the interaction coefficients, $\gamma_{s}$, in the following regression using specification (8) in Panel A of Table 6:

$E x W e i g h t_{i m t}=\alpha+\sum_{s=t-3}^{t+3}\left(\beta_{s} *\right.$ Event $_{m s}+\gamma_{s} * D_{i m} \times$ Event $\left._{m s}\right)+\delta * D_{i m}+$ Control $_{i, t-1}+\alpha^{F E}+\varepsilon_{i m t}$.

Event $_{m s}$ is a dummy variable indicating the number of months relative to the fund-specific lockdown shock. When $s=t$, it refers to the year-month when the zip code which fund $m$ is headquartered starts the executive order of lockdown. Ninety-five percent confidence intervals, adjusted for clustering at the fund level, are also plotted. 


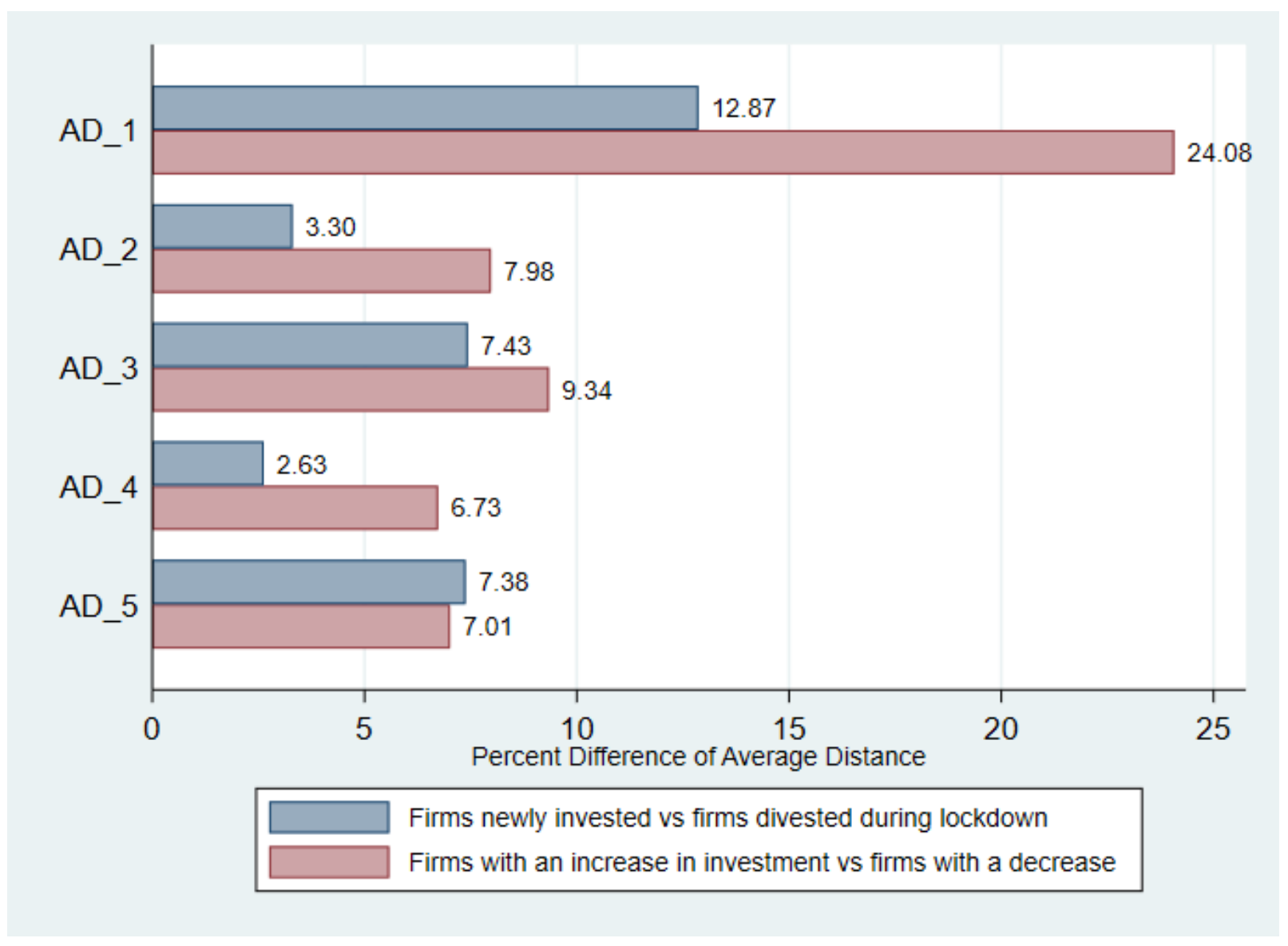

Figure 5: The Average Distance of Firms Invested vs Divested during Lockdown. We sort funds into five quintile portfolios according to their weighted average distance to holding firms as of March 2019: $A D \_1, \cdots, A D \_5$. Then we calculate the percentage difference of the average distance for two groups of firms for each fund within each portfolio: $100 \% *\left(\frac{\mathrm{AD} \text { of firms newly invested during lockdown }}{\mathrm{AD} \text { of firms divested during lockdown }}-1\right)$ in blue bars, and $100 \% *$ ( $\left.\frac{\mathrm{AD} \text { of existing firms with an increase in investment }}{\mathrm{AD} \text { of existing firms with a decrease in investment }}-1\right)$ in pink bars. The average distance is weighted by the excess portfolio weight between the fund and its benchmark on a given stock. 


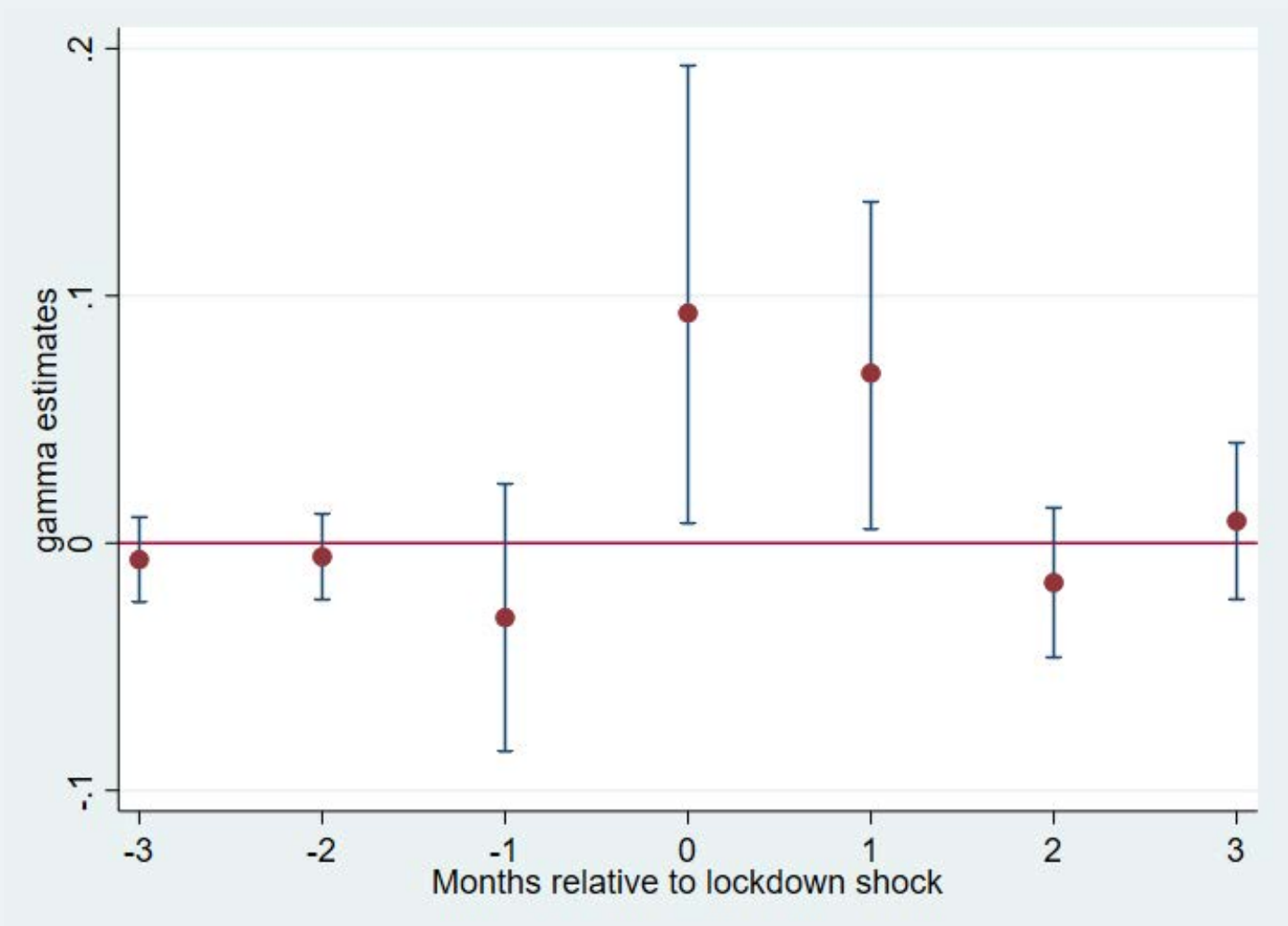

Figure 6: Risk Shifting

For each fund, we calculate the risk shifting measure in Equation (14) which compares the hypothetical portfolio's volatility based on the fund's previously disclosed holdings with the past realized volatility based on the fund's returns. A positive value of Risk Shift indicates that a fund takes actions to reduce risks. We sort funds into quintile portfolios according to their pre-pandemic weighted average distance to holding firms as of March 2019: $A D_{-} 1, \cdots, A D_{-} 5$. We report the point estimates, $\gamma_{s}$, in the following regression which captures the effect of funds' proximity investment preference on funds' risk shifting from three months before the lockdown shock through three months after:

$$
\text { Risk Shift }_{m t}=\alpha+\sum_{s=t-3}^{t+3}\left(\beta_{s} * \text { Event }_{m s}+\gamma_{s} * \text { LIFD }_{m} \times \text { Event }_{m s}\right)+\alpha^{F E}+\varepsilon_{m t} .
$$

$L I F D_{m}$ is a local-investing-fund dummy which is equal to one if a fund invests more in local stocks (Portfolio $A D_{-} 1$ ), and zero if a fund invests more in distant stocks (Portfolio $A D_{-} 5$ ). Ninety-five percent confidence intervals, adjusted for clustering at the fund family level, are also plotted. 


\section{Table 1: Summary Statistics}

Panel A of this table reports the characteristics of actively-managed U.S. equity mutual funds in our sample. For each fund, we identify its benchmark index according to MorningStar. Excess return is the difference between a fund's return and its benchmark index's return at the monthly frequency. Fund investment distance is defined in Equation (1). Fund concentration is the Herfindahl-Hirschman Index as the sum of squared holding weights. We calculate the fund-level active share in line with Cremers et al. (2016) and require funds to have at least $50 \%$ activeness to be qualified in our sample. Panel B reports the lockdown information. There were 33 states which embarked lockdown in March 2020, and another 12 states jointed the list in April 2020. Footprint activity is the total number of visits (in millions) within a month at a given zip code. We report the mean, median, standard deviation, the 25th and 75th percentile for footprint activities across all zip codes in our sample, where mutual funds management companies are headquartered.

Panel A: Mutual fund characteristics

\begin{tabular}{|c|c|c|c|c|c|c|c|}
\hline Variable & Mean & Median & STD & P10 & $\mathrm{P} 25$ & P75 & P90 \\
\hline & \multicolumn{7}{|c|}{ Before the lockdown: January 2019 - December 2019} \\
\hline Fund Return (\%) & 2.22 & 2.40 & 4.14 & -3.31 & 0.43 & 4.47 & 7.16 \\
\hline Excess Return (\%) & -0.05 & -0.08 & 1.75 & -1.84 & -0.89 & 0.76 & 1.89 \\
\hline Fund investment distance ('000 mile) & 1.09 & 1.05 & 0.33 & 0.72 & 0.87 & 1.24 & 1.57 \\
\hline Fund Concentration (\%) & 2.28 & 1.89 & 2.47 & 0.75 & 1.26 & 2.82 & 3.72 \\
\hline Fund Active Share (\%) & 80.99 & 82.20 & 17.20 & 56.58 & 68.14 & 93.65 & 98.61 \\
\hline \multirow[t]{2}{*}{ Fund AUM (\$bil) } & 2.29 & 0.38 & 8.17 & 0.03 & 0.08 & 1.57 & 4.99 \\
\hline & \multicolumn{7}{|c|}{ During the lockdown: March 2020 - June 2020} \\
\hline Fund Return (\%) & -1.21 & 2.08 & 12.33 & -19.58 & -12.20 & 7.47 & 13.37 \\
\hline Excess Return (\%) & -0.10 & -0.09 & 3.61 & -3.57 & -1.67 & 1.44 & 3.61 \\
\hline Fund investment distance ('000 mile) & 1.10 & 1.06 & 0.35 & 0.71 & 0.87 & 1.28 & 1.60 \\
\hline Fund Concentration $(\%)$ & 2.54 & 2.06 & 3.12 & 0.79 & 1.32 & 3.06 & 4.03 \\
\hline Fund Active Share (\%) & 79.80 & 80.52 & 17.62 & 54.27 & 66.01 & 93.60 & 99.02 \\
\hline Fund AUM (\$bil) & 2.15 & 0.31 & 7.97 & 0.02 & 0.07 & 1.33 & 4.61 \\
\hline
\end{tabular}

Panel B: Lockdown information

\begin{tabular}{|c|c|c|c|c|c|c|}
\hline & \multirow{2}{*}{$\begin{array}{l}\text { Num of States } \\
\text { in lockdown }\end{array}$} & \multicolumn{5}{|c|}{ Footprint Activity (mil) } \\
\hline & & Mean & Median & STD & P25 & P75 \\
\hline Dec 2019 & 0 & 0.156 & 0.114 & 0.145 & 0.078 & 0.195 \\
\hline Jan 2020 & 0 & 0.159 & 0.120 & 0.139 & 0.073 & 0.216 \\
\hline Feb 2020 & 0 & 0.139 & 0.103 & 0.120 & 0.068 & 0.194 \\
\hline Mar 2020 & 33 & 0.082 & 0.068 & 0.064 & 0.034 & 0.114 \\
\hline Apr 2020 & 45 & 0.025 & 0.017 & 0.024 & 0.006 & 0.032 \\
\hline May 2020 & 45 & 0.031 & 0.022 & 0.031 & 0.007 & 0.045 \\
\hline Jun 2020 & 45 & 0.048 & 0.037 & 0.041 & 0.012 & 0.073 \\
\hline
\end{tabular}




\section{Table 2: The Impact of Lockdown on Fund Return}

This table presents the regression results about the impact of lockdown on the returns of equity mutual funds:

$$
\operatorname{Ret}_{m t}=\alpha+\beta * \text { Lockdown }_{m t}+\gamma * A D_{m}^{\text {Mar2019 }} \times \text { Lockdown }_{m t}+\alpha_{m}+\alpha_{t}+\varepsilon_{m t} .
$$

We examine both a fund's raw return and its excess return after deducting its benchmark index's return. We identify the benchmark index for each equity fund according to fund information provided by MorningStar and require a fund to be qualified in our sample if it has active share larger than $50 \%$ in month $t . A D_{m}^{\text {Mar2019 }}$ is the weighted average investment distance in miles between the headquarters of fund $m$ 's management company and all its holding stocks, using the excess weight between fund m's holdings and corresponding benchmark index's holdings in March 2019. We consider two proxies for lockdown: the dummy variable Lockdown $n_{m t}$ which equals to 1 if the zip code in which fund $m$ 's management company headquartered is under the executive order of lockdown in month $t, 0$ otherwise, and the dummy variable Footprint $t_{m t}$ which equals to 1 if footprint activity in the fund $m$-located zip code in month $t$ encounters $30 \%$ retraction compared to the activity in the same zip code in March 2019. Standard errors are clustered at the fund family level, that is, the management company of funds. The sample period is from January 2019 to June 2020.

\begin{tabular}{|c|c|c|c|c|c|}
\hline & $\begin{array}{c}(1) \\
\text { Fund Ret }\end{array}$ & $\begin{array}{c}(2) \\
\text { Excess Ret }\end{array}$ & & $\begin{array}{c}(3) \\
\text { Fund Ret }\end{array}$ & $\begin{array}{c}(4) \\
\text { Excess Ret }\end{array}$ \\
\hline Lockdown & $\begin{array}{c}-0.2781 \\
(-0.44)\end{array}$ & $\begin{array}{c}-0.0925 \\
(-0.19)\end{array}$ & Footprint & $\begin{array}{c}-2.6229^{* * *} \\
(-5.86)\end{array}$ & $\begin{array}{c}-1.1899^{* * *} \\
(-3.58)\end{array}$ \\
\hline $\mathrm{AD} \times$ Lockdown & $\begin{array}{c}0.0016^{* * *} \\
(4.25)\end{array}$ & $\begin{array}{c}0.0006^{* * *} \\
(2.60)\end{array}$ & $\mathrm{AD} \times$ Footprint & $\begin{array}{c}0.0020^{* * *} \\
(4.97)\end{array}$ & $\begin{array}{c}0.0009^{* * *} \\
(3.43)\end{array}$ \\
\hline Fund FE & $\mathrm{Y}$ & $\mathrm{Y}$ & Fund FE & $\mathrm{Y}$ & $\mathrm{Y}$ \\
\hline Time FE & $\mathrm{Y}$ & $\mathrm{Y}$ & Time FE & $\mathrm{Y}$ & $\mathrm{Y}$ \\
\hline Obs & 14897 & 14885 & Obs & 15949 & 15935 \\
\hline $\operatorname{Adj} R^{2}$ & 0.886 & 0.112 & $\operatorname{Adj} R^{2}$ & 0.885 & 0.105 \\
\hline
\end{tabular}




\section{Table 3: Fund Performance: $\alpha$ and $\beta$ s before and during Lockdown}

This table presents the regression results that examine the impact of lockdown on fund performance proxied by alpha and betas:

$$
\alpha_{m t} \text { or } \beta_{m t}=a+b * \text { Footprint }_{m t}+\gamma * A D_{m}^{\text {Mar2019 }} \times \text { Footprint }_{m t}+Z_{m}+Z_{t}+\varepsilon_{m t} .
$$

Here $\alpha_{m t}$ and $\beta_{m t}$ are estimated monthly for fund $m$ by regressing daily fund returns on the daily risk factors in Fama and French (2015) within each month $t$ :

$$
\operatorname{Ret}_{m t d}=\alpha_{m t}+\beta_{m t}^{M K T} M k t_{t d}+\beta_{m t}^{S M B} S M B_{t d}+\beta_{m t}^{H M L} H M L_{t d}+\beta_{m t}^{R M W} R M W_{t d}+\beta_{m t}^{C M A} C M A_{t d}+\varepsilon_{m t d} .
$$

Panel B provides a snapshot which compares the alphas in March 2019 versus March 2020 for funds investing locally, those in Portfolio $A D \_1$, and funds investing far away, those in Portfolio $A D \_5$. These portfolios are constructed by sorting funds according to their average holding distance as of March 2019, based on the excess weight deviated from the benchmark index.

\begin{tabular}{|c|c|c|c|c|c|c|}
\hline & $\alpha$ & $\beta^{M k t R F}$ & $\beta^{S M B}$ & $\beta^{H M L}$ & $\beta^{R M W}$ & $\beta^{C M A}$ \\
\hline Footprint & $\begin{array}{c}-6.3895^{* * *} \\
(-4.43)\end{array}$ & $\begin{array}{l}1.9917 \\
(1.33)\end{array}$ & $\begin{array}{c}2.9469 \\
(1.53)\end{array}$ & $\begin{array}{c}1.1786 \\
(0.57)\end{array}$ & $\begin{array}{c}-4.5785^{*} \\
(-1.69)\end{array}$ & $\begin{array}{c}6.9104^{*} \\
(1.60)\end{array}$ \\
\hline $\mathrm{AD} \times$ Footprint & $\begin{array}{c}0.0053^{* * *} \\
(4.31)\end{array}$ & $\begin{array}{c}-0.0017 \\
(-1.38)\end{array}$ & $\begin{array}{c}-0.0032^{* * *} \\
(-2.16)\end{array}$ & $\begin{array}{l}0.0011 \\
(0.65)\end{array}$ & $\begin{array}{c}0.0019 \\
(0.88)\end{array}$ & $\begin{array}{c}-0.0102^{* * *} \\
(-3.40)\end{array}$ \\
\hline Fund FE & $\mathrm{Y}$ & $\mathrm{Y}$ & $\mathrm{Y}$ & $\mathrm{Y}$ & $\mathrm{Y}$ & $\mathrm{Y}$ \\
\hline Time FE & Y & $\mathrm{Y}$ & Y & $\mathrm{Y}$ & $\mathrm{Y}$ & $\mathrm{Y}$ \\
\hline Obs & 15550 & 15550 & 15550 & 15550 & 15550 & 15550 \\
\hline $\operatorname{Adj} R^{2}$ & 0.092 & 0.514 & 0.818 & 0.679 & 0.250 & 0.395 \\
\hline \multicolumn{7}{|l|}{ Panel B. $t$-test of alpha } \\
\hline & \multicolumn{3}{|c|}{ Local-Investing Funds $\left(A D \_1\right)$} & \multicolumn{3}{|c|}{ Distant-Investing Funds $\left(A D \_5\right)$} \\
\hline Alpha (bps) in March 2019 & & 1.47 & & & -0.57 & \\
\hline Alpha (bps) in March 2020 & & -3.08 & & & 0.18 & \\
\hline Difference & & 4.55 & & & -0.75 & \\
\hline$t$-statistics & & 4.03 & & & -0.87 & \\
\hline$p$-value & & 0.00 & & & 0.39 & \\
\hline
\end{tabular}

Panel A. Difference-in-difference regression 


\section{Table 4: Retest Fund Performance with the Paired Fund Sample}

The table repeats the regression tests in Table 2 for a unique paired fund sample in which each pair of funds are located in the same region but are affected differently by lockdown. The pairs defined being affected differently from lockdown have a difference in the footprint retraction for at least 20 percent, for example, one fund's zip-code has $-30 \%$ change in footprint activities while the other's one has $-5 \%$ change (the gap is $25 \%$ ), where the percentage change of footprint activities is between March 2019 and March 2020. We report results using two "nearby" definition, the paired funds are located within 100 miles (161 KM) in Panel A and within 20 miles (32 KM) in Panel B. All funds in the pairs have an active share larger than $50 \%$. In each pair, we assign the value of 1 to the fund whose zip-code suffers more from the lockdown, and 0 to the other fund. This indicator variable is denoted as Suffer. Standard errors are clustered at the fund family level. The sample period is from January 2019 to June 2020.

Panel A. Paired funds with adjacency $<100 \mathrm{~m}$ and activity gap $>20 \%$

\begin{tabular}{|c|c|c|c|c|c|}
\hline & Fund Ret & Excess Ret & & Fund Ret & Excess Ret \\
\hline Lockdown & $\begin{array}{c}-1.4647 \\
(-1.59)\end{array}$ & $\begin{array}{c}0.8443 \\
(1.37)\end{array}$ & Footprint & $\begin{array}{c}-3.1718^{* * *} \\
(-4.66)\end{array}$ & $\begin{array}{c}-0.9957^{* *} \\
(-2.06)\end{array}$ \\
\hline $\mathrm{AD} \times$ Lockdown & $\begin{array}{c}0.0029^{* * *} \\
(6.66)\end{array}$ & $\begin{array}{c}0.0007^{* *} \\
(2.15)\end{array}$ & $\mathrm{AD} \times$ Footprint & $\begin{array}{c}0.0027^{* * *} \\
(5.28)\end{array}$ & $\begin{array}{c}0.0008^{* * *} \\
(2.35)\end{array}$ \\
\hline Suffer Dummy & $\begin{array}{c}-0.0138 \\
(-0.85)\end{array}$ & $\begin{array}{c}-0.0173 \\
(-1.13)\end{array}$ & Suffer Dummy & $\begin{array}{c}-0.0040 \\
(-0.26)\end{array}$ & $\begin{array}{r}-0.0091 \\
(-0.69)\end{array}$ \\
\hline Fund FE & $\mathrm{Y}$ & $\mathrm{Y}$ & Fund FE & $\mathrm{Y}$ & $\mathrm{Y}$ \\
\hline Time FE & $\mathrm{Y}$ & $\mathrm{Y}$ & Time FE & $\mathrm{Y}$ & $\mathrm{Y}$ \\
\hline Obs & 771255 & 770462 & Obs & 771255 & 770462 \\
\hline $\operatorname{Adj} R^{2}$ & 0.900 & 0.212 & $\operatorname{Adj} R^{2}$ & 0.898 & 0.205 \\
\hline \multicolumn{6}{|c|}{ Panel B. Paired funds with adjacency $<20 m$ and activity gap $>20 \%$} \\
\hline & Fund Ret & Excess Ret & & Fund Ret & Excess Ret \\
\hline Lockdown & $\begin{array}{c}-0.7351 \\
(-0.47)\end{array}$ & $\begin{array}{c}-0.3173 \\
(-0.34)\end{array}$ & Footprint & $\begin{array}{c}-2.9034^{* *} \\
(-2.25)\end{array}$ & $\begin{array}{c}-2.9882^{* * *} \\
(-3.90)\end{array}$ \\
\hline $\mathrm{AD} \times$ Lockdown & $\begin{array}{c}0.0011^{*} \\
(1.75)\end{array}$ & $\begin{array}{c}0.0006^{*} \\
(1.65)\end{array}$ & $\mathrm{AD} \times$ Footprint & $\begin{array}{c}0.0012^{*} \\
(1.79)\end{array}$ & $\begin{array}{c}0.0011^{* * *} \\
(2.42)\end{array}$ \\
\hline Suffer Dummy & $\begin{array}{c}-0.0092 \\
(-0.05)\end{array}$ & $\begin{array}{c}-0.0500 \\
(-0.41)\end{array}$ & Suffer Dummy & $\begin{array}{c}-0.0081 \\
(-0.08)\end{array}$ & $\begin{array}{c}-0.0535 \\
(-0.73)\end{array}$ \\
\hline Fund FE & $\mathrm{Y}$ & $\mathrm{Y}$ & Fund FE & $\mathrm{Y}$ & $\mathrm{Y}$ \\
\hline Time FE & $\mathrm{Y}$ & $\mathrm{Y}$ & Time FE & $\mathrm{Y}$ & $\mathrm{Y}$ \\
\hline Obs & 82841 & 82826 & Obs & 82841 & 82826 \\
\hline Adj $R^{2}$ & 0.901 & 0.240 & $\operatorname{Adj} R^{2}$ & 0.902 & 0.256 \\
\hline
\end{tabular}




\section{Table 5: The Impact of Lockdown on Firm Return Prediction based on Local Funds' Holdings}

This table examines the impact of lockdown on the predictive power of local funds' portfolio allocation on holding firms' returns:

$$
\begin{aligned}
\text { FirmRet }_{i t+1}= & \alpha+\beta * \Delta \text { ExWeight }_{\text {imt }}^{\text {Local }}+\gamma * \Delta \text { ExWeight }_{\text {imt }}^{\text {Local }} \times \text { FirmLockdown }_{i t} \\
& + \text { FirmLockdown }_{i t}+\text { FirmRet }_{i t}+\alpha^{F E}+\varepsilon_{i t} .
\end{aligned}
$$

For each firm in month $t$, we identify funds which hold the firm and also have the headquarters located within 250 miles from the headquarter of the firms and label these funds as local funds. $\Delta$ ExWeight is the monthly change of excess weight which extracts the benchmark index's weight on stock $i$ from the local fund's holding weight on the same stock. We use two proxies for lockdown: the dummy variable Firm Lockdown $i$ which equals to 1 if the zip code in which firm $i$ headquartered is under the executive order of lockdown in month $t, 0$ otherwise, and the dummy variable Firm Footprint ${ }_{i t}$ which equals to 1 if footprint activity in the firm $i$-located zip code in month $t$ encounters $30 \%$ retraction compared to the activity in the same zip code in March 2019. The regression controls for a firm's current return. We also control for the industry, firm, and fund $\times$ time (year-month) fixed effects. Standard errors are clustered at the fund $\times$ time and industry level. The sample period is from January 2019 to June 2020.

\begin{tabular}{lclc}
\hline$\Delta$ ExWeight by Local Funds & $\begin{array}{c}0.5694^{* *} \\
(2.24)\end{array}$ & ExWeight by Local Funds & $\begin{array}{c}0.5522^{* * *} \\
(2.24)\end{array}$ \\
$\Delta$ ExWeight $\times$ Firm Lockdown & $\begin{array}{c}-1.0488^{*} \\
(-2.18)\end{array}$ & $\Delta$ ExWeight $\times$ Firm Footprint & $\begin{array}{c}-0.9549^{*} \\
(-2.18)\end{array}$ \\
& -0.4909 & Firm Footprint & 0.5813 \\
Firm Lockdown & $(-0.36)$ & & $(0.88)$ \\
& $-0.0935^{* * *}$ & Firm Return $(\mathrm{t})$ & $-0.0928^{* * *}$ \\
Firm Return (t) & $(-8.35)$ & & $(-8.31)$ \\
& & Fixed Effect & $\mathrm{Y}$ \\
Fixed Effect & $\mathrm{Y}$ & Industry & $\mathrm{Y}$ \\
Industry & $\mathrm{Y}$ & Firm & $\mathrm{Y}$ \\
Firm & $\mathrm{Y}$ & Fund Time & 507418 \\
Fund*Time & 496002 & Obs & 0.353 \\
Obs & 0.349 & Adj $R^{2}$ & \\
Adj $R^{2}$ & & &
\end{tabular}




\section{Table 6: The Impact of Lockdown on Fund Investment}

This table presents the regression results which examines the impact of lockdown on fund portfolio's asset allocation:

Weight $_{i m t}=\alpha+\beta *$ Lockdown $_{m t}+\gamma * D_{i m} \times$ Lockdown $_{m t}+\delta * D_{i m}+$ Control $_{i t-1}+\alpha^{F E}+\varepsilon_{i m t}$.

We examine both fund weight and excess weight on stock $i$ by fund $m$ in month $t$, where excess weight extracts the benchmark index's weight on stock $i$ from the fund portfolio's holding weight on the same stock. $D_{i m}$ is the distance in '000 miles between the headquarters of fund $m$ 's management company and stock $i$ 's issue firm. Panels A and B show the results under two proxies for lockdown, respectively: the dummy variable Lockdown $\mathbf{n}_{\mathbf{m t}}$ which equals to 1 if the zip code in which fund $m$ 's management company headquartered is under the executive order of lockdown in month $t, 0$ otherwise, and the dummy variable Footprint $_{\mathbf{m t}}$ which equals to 1 if footprint activity in the fund $m$-located zip code in month $t$ encounters $30 \%$ retraction compared to the activity in the same zip code in March 2019. The various sets of control variables include the previous month's firm return $(R E T)$ and the previous quarter's firm characteristics such as the log of total asset $(S I Z E)$ and the return on assets $(R O A)$. We also consider controlling for the lockdown situation in firm $i$-located

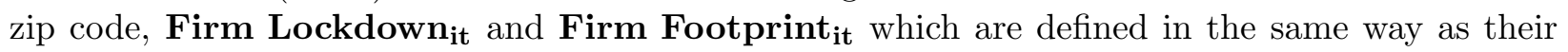
counterparts Lockdown $_{m t}$ and Footprint $m t$ except substituting funds' zip codes to firms' zip codes. We also control for the fund, industry $\times$ time (year-month), and firm fixed effects. Standard errors are clustered at the fund level. The sample period is from January 2019 to June 2020. 
Panel A. Lockdown is proxied by executive order

\begin{tabular}{|c|c|c|c|c|c|c|c|c|}
\hline & \multicolumn{4}{|c|}{ Fund weight } & \multicolumn{4}{|c|}{ Excess weight } \\
\hline & $(1)$ & $(2)$ & (3) & $(4)$ & $(5)$ & (6) & $(7)$ & $(8)$ \\
\hline Lockdown $_{m t}$ & $\begin{array}{c}-0.0072 \\
(-1.12)\end{array}$ & $\begin{array}{c}-0.0059 \\
(-0.93)\end{array}$ & $\begin{array}{r}-0.0077 \\
(-1.19)\end{array}$ & $\begin{array}{c}-0.0064 \\
(-1.01)\end{array}$ & $\begin{array}{c}-0.0028 \\
(-0.45)\end{array}$ & $\begin{array}{c}-0.0021 \\
(-0.34)\end{array}$ & $\begin{array}{c}-0.0032 \\
(-0.51)\end{array}$ & $\begin{array}{c}-0.0025 \\
(-0.41)\end{array}$ \\
\hline $\mathrm{D}^{*}$ Lockdown $_{m t}$ & $\begin{array}{c}0.0110^{* * *} \\
(5.70)\end{array}$ & $\begin{array}{c}0.0102^{* * *} \\
(5.34)\end{array}$ & $\begin{array}{c}0.0104^{* * *} \\
(5.42)\end{array}$ & $\begin{array}{c}0.0097^{* * *} \\
(5.06)\end{array}$ & $\begin{array}{c}0.0050^{* * *} \\
(2.82)\end{array}$ & $\begin{array}{c}0.0047^{* * *} \\
(2.61)\end{array}$ & $\begin{array}{c}0.0045^{* *} \\
(2.50)\end{array}$ & $\begin{array}{c}0.0041^{* *} \\
(2.29)\end{array}$ \\
\hline $\mathrm{D}_{i m}$ & $\begin{array}{c}0.0047^{*} \\
(1.65)\end{array}$ & $\begin{array}{c}0.0049^{*} \\
(1.71)\end{array}$ & $\begin{array}{c}0.0047 \\
(1.64)\end{array}$ & $\begin{array}{c}0.0049^{*} \\
(1.70)\end{array}$ & $\begin{array}{c}0.0010 \\
(0.33)\end{array}$ & $\begin{array}{c}0.0014 \\
(0.46)\end{array}$ & $\begin{array}{c}0.0010 \\
(0.31)\end{array}$ & $\begin{array}{c}0.0014 \\
(0.45)\end{array}$ \\
\hline Firm Lockdown ${ }_{i t}$ & & $\begin{array}{c}0.0100^{* * *} \\
(3.03)\end{array}$ & & $\begin{array}{c}0.0079^{* *} \\
(2.42)\end{array}$ & & $\begin{array}{l}0.0036 \\
(1.12)\end{array}$ & & $\begin{array}{c}0.0018 \\
(0.57)\end{array}$ \\
\hline 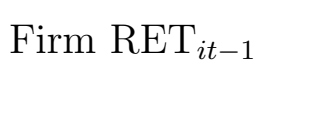 & & & $\begin{array}{c}0.0018^{* * *} \\
(15.82)\end{array}$ & $\begin{array}{c}0.0018^{* * *} \\
(15.75)\end{array}$ & & & $\begin{array}{c}0.0015^{* * *} \\
(13.85)\end{array}$ & $\begin{array}{c}0.0015^{* * *} \\
(13.77)\end{array}$ \\
\hline Firm SIZE $_{i t-1}$ & & & $\begin{array}{c}0.0254^{* * *} \\
(4.61)\end{array}$ & $\begin{array}{c}0.0265^{* * *} \\
(4.77)\end{array}$ & & & $\begin{array}{c}0.0176^{* * *} \\
(3.14)\end{array}$ & $\begin{array}{c}0.0187^{* * *} \\
\quad(3.30)\end{array}$ \\
\hline Firm $\mathrm{ROA}_{i t-1}$ & & & $\begin{array}{c}0.0935^{* * *} \\
(5.78)\end{array}$ & $\begin{array}{c}0.0924^{* * *} \\
(5.71)\end{array}$ & & & $\begin{array}{c}0.0834^{* * *} \\
(5.19)\end{array}$ & $\begin{array}{c}0.0824^{* * *} \\
(5.12)\end{array}$ \\
\hline Fixed Effect & & & & & & & & \\
\hline Industry $\times$ time & $\mathrm{Y}$ & $\mathrm{Y}$ & $\mathrm{Y}$ & $\mathrm{Y}$ & $\mathrm{Y}$ & $\mathrm{Y}$ & $\mathrm{Y}$ & $\mathrm{Y}$ \\
\hline Firm & $\mathrm{Y}$ & $\mathrm{Y}$ & $\mathrm{Y}$ & $\mathrm{Y}$ & $\mathrm{Y}$ & $\mathrm{Y}$ & $\mathrm{Y}$ & $\mathrm{Y}$ \\
\hline Fund & Y & Y & $\mathrm{Y}$ & $\mathrm{Y}$ & Y & $\mathrm{Y}$ & $\mathrm{Y}$ & $\mathrm{Y}$ \\
\hline Obs & 1893409 & 1851635 & 1872040 & 1831527 & 1893409 & 1851635 & 1872040 & 1831527 \\
\hline $\operatorname{Adj} R^{2}$ & 0.671 & 0.671 & 0.671 & 0.671 & 0.571 & 0.573 & 0.571 & 0.573 \\
\hline
\end{tabular}


Panel B. Lockdown is proxied by the contraction of footprint activities

\begin{tabular}{|c|c|c|c|c|c|c|c|c|}
\hline & \multicolumn{4}{|c|}{ Fund weight } & \multicolumn{4}{|c|}{ Excess weight } \\
\hline & (1) & $(2)$ & $(3)$ & $(4)$ & $(5)$ & (6) & $(7)$ & $(8)$ \\
\hline Footprint $_{m t}$ & $\begin{array}{c}-0.0151^{* *} \\
(-2.08)\end{array}$ & $\begin{array}{c}-0.0149 * * \\
(-2.06)\end{array}$ & $\begin{array}{c}-0.0147^{* *} \\
(-2.01)\end{array}$ & $\begin{array}{c}-0.0145^{* *} \\
(-1.99)\end{array}$ & $\begin{array}{c}-0.0048 \\
(-0.72)\end{array}$ & $\begin{array}{c}-0.0048 \\
(-0.71)\end{array}$ & $\begin{array}{c}-0.0043 \\
(-0.64)\end{array}$ & $\begin{array}{c}-0.0043 \\
(-0.63)\end{array}$ \\
\hline $\mathrm{D}^{*}$ Footprint $_{m t}$ & $\begin{array}{c}0.0085^{* * *} \\
(4.08)\end{array}$ & $\begin{array}{c}0.0084^{* * *} \\
(4.03)\end{array}$ & $\begin{array}{c}0.0080^{* * *} \\
(3.81)\end{array}$ & $\begin{array}{c}0.0078^{* * *} * \\
(3.75)\end{array}$ & $\begin{array}{c}0.0037^{*} \\
(1.88)\end{array}$ & $\begin{array}{c}0.0037^{*} \\
(1.86)\end{array}$ & $\begin{array}{c}0.0032^{*} \\
(1.69)\end{array}$ & $\begin{array}{c}0.0031^{*} \\
(1.68)\end{array}$ \\
\hline $\mathrm{D}_{i m}$ & $\begin{array}{c}0.0049^{*} \\
(1.71)\end{array}$ & $\begin{array}{c}0.0049^{*} \\
(1.72)\end{array}$ & $\begin{array}{c}0.0049^{*} \\
(1.70)\end{array}$ & $\begin{array}{c}0.0049^{*} \\
(1.71)\end{array}$ & $\begin{array}{c}0.0009 \\
(0.30)\end{array}$ & $\begin{array}{c}0.0009 \\
(0.30)\end{array}$ & $\begin{array}{c}0.0009 \\
(0.29)\end{array}$ & $\begin{array}{c}0.0009 \\
(0.29)\end{array}$ \\
\hline Firm Footprint $_{i t}$ & & $\begin{array}{c}0.0115^{* * *} \\
(4.30)\end{array}$ & & $\begin{array}{c}0.0113^{* * *} \\
(4.22)\end{array}$ & & $\begin{array}{l}0.0036 \\
(1.40)\end{array}$ & & $\begin{array}{c}0.0033 \\
(1.27)\end{array}$ \\
\hline Firm $\mathrm{RET}_{i t-1}$ & & & $\begin{array}{c}0.0019 * * * \\
(16.36)\end{array}$ & $\begin{array}{c}0.0019^{* * *} * \\
(16.36)\end{array}$ & & & $\begin{array}{c}0.0015^{* * *} \\
(14.37)\end{array}$ & $\begin{array}{c}0.0015^{* * *} \\
(14.37)\end{array}$ \\
\hline Firm SIZE $_{i t-1}$ & & & $\begin{array}{c}0.0255^{* * *} \\
(4.74)\end{array}$ & $\begin{array}{c}0.0256^{* * *} \\
(4.75)\end{array}$ & & & $\begin{array}{c}0.0186^{* * * *} \\
(3.39)\end{array}$ & $\begin{array}{c}0.0186^{* * * *} \\
(3.39)\end{array}$ \\
\hline Firm $\mathrm{ROA}_{i t-1}$ & & & $\begin{array}{c}0.0950^{* * *} \\
(5.94)\end{array}$ & $\begin{array}{c}0.0945^{* * *} \\
(5.92)\end{array}$ & & & $\begin{array}{c}0.0837^{* * *} \\
(5.28)\end{array}$ & $\begin{array}{c}0.0835^{* * *} \\
\quad(5.27)\end{array}$ \\
\hline Fixed Effect & & & & & & & & \\
\hline Industry $\times$ time & $\mathrm{Y}$ & $\mathrm{Y}$ & $\mathrm{Y}$ & $\mathrm{Y}$ & $\mathrm{Y}$ & $\mathrm{Y}$ & $\mathrm{Y}$ & $\mathrm{Y}$ \\
\hline Firm & $\mathrm{Y}$ & $\mathrm{Y}$ & $\mathrm{Y}$ & $\mathrm{Y}$ & $\mathrm{Y}$ & $\mathrm{Y}$ & $\mathrm{Y}$ & $\mathrm{Y}$ \\
\hline Fund & $\mathrm{Y}$ & $\mathrm{Y}$ & $\mathrm{Y}$ & $\mathrm{Y}$ & $\mathrm{Y}$ & $\mathrm{Y}$ & $\mathrm{Y}$ & $\mathrm{Y}$ \\
\hline Obs & 1985099 & 1985099 & 1962848 & 1962848 & 1985099 & 1985099 & 1962848 & 1962848 \\
\hline $\operatorname{Adj} R^{2}$ & 0.672 & 0.672 & 0.672 & 0.672 & 0.570 & 0.570 & 0.570 & 0.570 \\
\hline
\end{tabular}




\section{Table 7: The Impact of Lockdown on Fund Activeness in Local Stocks}

This table presents the regression results which examines the impact of lockdown on fund activeness in local stocks:

$$
\text { Active_in_Local }{ }_{m t}=\alpha+\beta * \text { Lockdown }_{m t}+\gamma * \text { Lockdown } n_{m t} \times L I F D_{m}+\alpha_{m}+\alpha_{t}+\varepsilon_{m t} \text {. }
$$

Active_in_Local is the degree of activeness in local stocks held by fund $m$ in month $t$, which is defined as the average absolute deviation between the percentage investment in local stocks of the fund and the percentage investment by the fund's benchmark index. For each fund, we categorize the stocks in its holdings as local stocks if the stock's issue firm is located within 250 miles from the fund's management company. We sort funds into quintile portfolios based on their pre-pandemic average holding distance as of March 2019, AD_1, $A D \_2, \ldots, A D \_5 . \quad L I F D_{m}$ is a local-investingfund dummy which is equal to one if a fund invests more in local stocks (in the portfolio $A D_{-} 1$ ), and zero if a fund invests more in distant stocks (in the portfolio $A D \_5$ ). We consider two proxies for lockdown: the dummy variable Lockdown $n_{m t}$ which equals to 1 if the zip code in which fund $m$ 's management company headquartered is under the executive order of lockdown in month $t, 0$ otherwise, and the dummy variable Footprint Ft $_{m}$ which equals to 1 if footprint activity in the fund $m$-located zip code in month $t$ encounters $30 \%$ retraction compared to the activity in the same zip code in March 2019. We control for the fund and time (year-month) fixed effects. Standard errors are clustered at the fund family level. The sample period is from January 2019 to June 2020.

\begin{tabular}{lclc}
\hline Lockdown & $1.2771^{* *}$ & Footprint & 0.3622 \\
& $(2.27)$ & & $(0.65)$ \\
Lockdown* LIFD & $-1.3391^{* * *}$ & Footprint* LIFD & $-1.1043^{* * *}$ \\
& $(-2.59)$ & & $(-2.59)$ \\
Fund FE & $\mathrm{Y}$ & Fund FE & $\mathrm{Y}$ \\
Time FE & $\mathrm{Y}$ & Time FE & $\mathrm{Y}$ \\
Obs & 6376 & Obs & 6376 \\
Adj $R^{2}$ & 0.935 & Adj $R^{2}$ & 0.935 \\
\hline
\end{tabular}




\section{Table 8: Evidence of Using Hard Information During Lockdown}

This table provides two evidence that funds using the strategy of proximity investment before the pandemic tend to use more hard information during lockdown. Panel A shows the characteristics of newly-invested firms versus divested firms during lockdown for local-investing funds and distant-investing funds, respectively. We report two firm characteristics, the dispersion of analysts forecasts which is calculated as the standard deviation of forecasts divided by the absolute value of mean forecast on a firm's one-quarter ahead earnings per share (EPS), and the forecast error which is calculated as the absolute deviation of the mean forecast and the actual value. Panel B presents $t$-test results on the reliance on public information (RPI) in March 2019 versus March 2020 for local-investing funds and distant-investing funds. RPI is calculated as the R-square value in regression (12), following the method in Kacperczyk and Seru (2007). RPI estimates the proportion of the change of fund portfolio allocations attributed to the change in analysts' recommendations. We sort funds into quintile portfolios according to their average holding distance as of March 2019, based on the excess weight deviated from the benchmark index, and denote funds in Portfolio $A D \_1$ as local-investing funds and those in Portfolio $A D \_5$ as distant-investing funds.

Panel A. Characteristics of newly-invested firms versus divested firms during lockdown

\begin{tabular}{|c|c|c|c|c|}
\hline \multirow[b]{3}{*}{ Firms newly invested in lockdown } & \multicolumn{2}{|c|}{ Local-Investing Funds } & \multicolumn{2}{|c|}{ Distant-Investing Funds } \\
\hline & Dispersion & Forecast Error & Dispersion & Forecast Error \\
\hline & 0.1168 & 0.1258 & 0.1283 & 0.1792 \\
\hline Firms divested in lockdown & 0.1289 & 0.1601 & 0.1285 & 0.6405 \\
\hline Difference & -0.0121 & -0.0343 & -0.0002 & -0.4613 \\
\hline$t$-statistics & -1.4048 & -2.6612 & -0.0253 & -1.0494 \\
\hline$p$-value $(\mathrm{H} 0:$ Diff $=0, \mathrm{H} 1:$ Diff $<0)$ & 0.0808 & 0.0042 & 0.4899 & 0.1480 \\
\hline
\end{tabular}

Panel B. T-test of reliance on public information before and during lockdown

\begin{tabular}{rccccc}
\hline & \multicolumn{2}{c}{ Local-Investing Funds } & & \multicolumn{2}{c}{ Distant-Investing Funds } \\
& \#Funds & Mean & & \#Funds & Mean \\
\cline { 2 - 3 } \cline { 5 - 6 } RPI as of March 2020 & 253 & 0.0245 & & 239 & 0.0305 \\
RPI as of March 2019 & 253 & 0.0182 & & 239 & 0.0267 \\
Difference & & 0.0063 & & & 0.0038 \\
$t$-statistics & & 1.7723 & & & 0.5765 \\
$p$-value (H0: Diff=0, H1: Diff $>0)$ & & 0.0388 & & & 0.2824 \\
\hline
\end{tabular}




\section{Table 9: The Impact of Lockdown on Fund Concentration}

This table presents the regression results which examines the impact of lockdown on fund concentration:

$$
H H I_{m t}=\alpha+\beta * \text { Lockdown }_{m t}+\gamma * \text { Lockdown }_{m t} \times L I F D_{m}+\delta * L I F D_{m}+\alpha_{m}+\alpha_{t}+\varepsilon_{m t} .
$$

$H H I_{m t}$ is fund $m$ 's Herfindahl-Hirschman Index in month $t$, which is defined as the sum of squared holding weights. In Panel A, HHI is calculated using all holding weights whereas in Panel B, HHI is calculated using top ten largest holding weights. We sort funds into quintile portfolios based on their pre-pandemic weighted average distance to holding firms as of March 2019. LIFD $D_{m}$ is an indicator variable for the local-investing funds, which is equal to one if a fund invests more in local stocks (Portfolio $A D \_1$ ), and zero if a fund invests more in distant stocks (Portfolio $A D \_5$ ). We consider two proxies for lockdown: the dummy variable Lockdown $n_{m t}$ which equals to 1 if the zip code in which fund $m$ 's management company headquartered is under the executive order of lockdown in month $t, 0$ otherwise, and the dummy variable Footprint ${ }_{m t}$ which equals to 1 if footprint activity in the fund $m$-located zip code in month $t$ encounters $30 \%$ retraction compared to the activity in the same zip code in March 2019. We also control for the fund and time (year-month) fixed effects. Standard errors are clustered at the fund family level. The sample period is from January 2019 to June 2020.

\begin{tabular}{lclc}
\hline \multicolumn{2}{l}{ Panel A. HHI is calculated using all holding weights } & & \\
\hline Lockdown & 0.0500 & Footprint & $0.0919^{* *}$ \\
& $(1.05)$ & & $(2.41)$ \\
Lockdown * LIFD & $-0.1565^{* * *}$ & Footprint * LIFD & $-0.1456^{* * *}$ \\
& $(-4.28)$ & & $(-4.06)$ \\
Fund FE & Y & Fund FE & Y \\
Time FE & Y & Time FE & Y \\
Obs & 6399 & Obs & 6399 \\
Adj $R^{2}$ & 0.943 & Adj $R^{2}$ & 0.942 \\
\hline
\end{tabular}

Panel B. HHI is calculated using top 10 largest holding weights

\begin{tabular}{lclc}
\hline Lockdown & 0.0150 & Footprint & 0.0078 \\
& $(0.22)$ & & $(0.14)$ \\
Lockdown * LIFD & $-0.2087^{* * *}$ & Footprint * LIFD & $-0.2009^{* * *}$ \\
& $(-3.95)$ & & $(-3.83)$ \\
Fund FE & $\mathrm{Y}$ & Fund FE & Y \\
Time FE & $\mathrm{Y}$ & Time FE & Y \\
Obs & 6383 & Obs & 6383 \\
Adj $R^{2}$ & 0.946 & Adj $R^{2}$ & 0.946 \\
\hline
\end{tabular}




\section{Table 10: The Channels of the Lockdown Impact}

Panel A examines the channels of the lockdown impact by repeating the main analysis for different types of footprint activities:

$$
\text { ExRet }_{m t}=\alpha+\beta * \text { Activity }_{m t}^{k}+\gamma * A D_{m}^{\text {Mar2019 }} \times \text { Activity }_{m t}^{k}+\alpha_{m}+\alpha_{t}+\varepsilon_{m t} .
$$

Activity $y_{m t}^{k}$ is defined as the product of -1 and the log of the number of visits to a specific group of brands in the fund $m$-located zip code in month $t$. Multiplying by -1 makes the interpretation of the variable consistent with two other proxies of lockdown in previous tables. Activity indeed measures the contraction of foot print activities; the less foot traffic activities there are in a zip code, the larger the variable "Activity" is. Panel A categorizes the brands by the first two-digit of NAICS codes and contains 13 gross industries listed below. Panel B runs a horse race regression for industry categories in Panel A, excluding the categories with less than 10,000 observations in the sample.

$$
\text { ExRet }_{m t}=\alpha+\sum_{k=1}^{K}\left(\beta_{k} * \text { Activity }_{m t}^{k}+\gamma_{k} * A D_{m}^{\text {Mar2019 }} \times \text { Activity }_{m t}^{k}\right)+\alpha_{m}+\alpha_{t}+\varepsilon_{m t}
$$

Panel $\mathrm{C}$ refines the categorization by the four-digit of NAICS codes within the general service category. Standard errors are clustered at the fund family level. The sample period is from January 2019 to June 2020.

\begin{tabular}{ll}
\hline 2-digit NAICS & Industry \\
\hline $31-33$ & Manufacturing \\
42 & Wholesale Trade \\
$44-45$ & Retail Trade \\
$48-49$ & Transportation and Warehousing \\
51 & Information \\
52 & Finance and Insurance \\
53 & Real Estate Rental and Leasing \\
61 & Educational Services \\
62 & Health Care and Social Assistance \\
71 & Arts, Entertainment, \& Recreation \\
72 & Accommodation and Food Services \\
81 & Other Services (except PA) \\
92 & Public Administration \\
\hline
\end{tabular}


Panel A: 13 gross categories

\begin{tabular}{|c|c|c|c|c|c|c|c|c|c|c|c|c|c|}
\hline & Mfg & $\begin{array}{c}\text { Wholesale } \\
\text { Trade }\end{array}$ & $\begin{array}{l}\text { Retail } \\
\text { Trade }\end{array}$ & $\begin{array}{l}\text { Trans } \\
\text { Wareh }\end{array}$ & Info & $\begin{array}{l}\text { Fin \& } \\
\text { Ins }\end{array}$ & $\begin{array}{l}\text { Real } \\
\text { Estate }\end{array}$ & $\begin{array}{c}\text { Edu } \\
\text { Service }\end{array}$ & $\begin{array}{l}\text { Health } \\
\text { Care }\end{array}$ & $\begin{array}{c}\text { Entm \& } \\
\text { Rec }\end{array}$ & $\begin{array}{c}\text { Accom \& } \\
\text { Food }\end{array}$ & $\begin{array}{l}\text { Other } \\
\text { Service }\end{array}$ & Others \\
\hline Activity & $\begin{array}{c}-0.6845^{* * *} \\
(-3.15)\end{array}$ & $\begin{array}{c}-0.6205^{* * *} \\
(-3.47)\end{array}$ & $\begin{array}{c}-0.5286^{* *} \\
(-2.13)\end{array}$ & $\begin{array}{c}-0.4417^{* *} \\
(-2.37)\end{array}$ & $\begin{array}{c}-0.3247^{* *} \\
(-2.10)\end{array}$ & $\begin{array}{c}-0.3797^{* *} \\
(-2.07)\end{array}$ & $\begin{array}{c}-0.2705 \\
(-1.25)\end{array}$ & $\begin{array}{c}-0.0269 \\
(-0.08)\end{array}$ & $\begin{array}{c}-0.3900 * * \\
(-2.39)\end{array}$ & $\begin{array}{c}-0.4653^{* *} \\
(-2.56)\end{array}$ & $\begin{array}{c}-0.4126^{* *} \\
(-2.15)\end{array}$ & $\begin{array}{c}-0.4795^{* *} \\
(-2.02)\end{array}$ & $\begin{array}{c}-0.2339 \\
(-0.69)\end{array}$ \\
\hline $\mathrm{AD} \times$ Activity & $\begin{array}{c}0.0007^{* * * *} \\
(3.25)\end{array}$ & $\begin{array}{c}0.0006^{* * *} \\
(3.49)\end{array}$ & $\begin{array}{c}0.0005^{* *} \\
(2.53)\end{array}$ & $\begin{array}{c}0.0004^{* *} \\
(2.40)\end{array}$ & $\begin{array}{c}0.0003^{* *} \\
(2.33)\end{array}$ & $\begin{array}{c}0.0003^{* *} \\
(2.19)\end{array}$ & $\begin{array}{c}0.0003^{* *} \\
(2.07)\end{array}$ & $\begin{array}{c}0.0002 \\
(0.50)\end{array}$ & $\begin{array}{c}0.0003^{* *} \\
(2.06)\end{array}$ & $\begin{array}{c}0.0004^{* * *} \\
(3.05)\end{array}$ & $\begin{array}{c}0.0005^{* * *} \\
(3.15)\end{array}$ & $\begin{array}{c}0.0004^{*} \\
(1.87)\end{array}$ & $\begin{array}{c}0.0002 \\
(0.76)\end{array}$ \\
\hline Fund Dummy & $\mathrm{Y}$ & $\mathrm{Y}$ & $\mathrm{Y}$ & $\mathrm{Y}$ & $\mathrm{Y}$ & $\mathrm{Y}$ & $\mathrm{Y}$ & $\mathrm{Y}$ & Y & $\mathrm{Y}$ & $\mathrm{Y}$ & $\mathrm{Y}$ & $\mathrm{Y}$ \\
\hline Time Dummy & $\mathrm{Y}$ & $\mathrm{Y}$ & $\mathrm{Y}$ & $\mathrm{Y}$ & $\mathrm{Y}$ & $\mathrm{Y}$ & $\mathrm{Y}$ & $\mathrm{Y}$ & $\mathrm{Y}$ & $\mathrm{Y}$ & $\mathrm{Y}$ & $\mathrm{Y}$ & $\mathrm{Y}$ \\
\hline Obs & 7600 & 7502 & 13163 & 11134 & 10008 & 12417 & 10090 & 3716 & 11713 & 11213 & 14264 & 7811 & 5674 \\
\hline $\operatorname{Adj} R^{2}$ & 0.111 & 0.093 & 0.103 & 0.093 & 0.102 & 0.101 & 0.100 & 0.119 & 0.100 & 0.104 & 0.112 & 0.096 & 0.090 \\
\hline
\end{tabular}

Panel B: Horse race in one regression (excluding industries with fewer than 10,000 obs)

\begin{tabular}{|c|c|c|c|c|c|c|c|c|}
\hline & $\begin{array}{l}\text { Retail } \\
\text { Trade }\end{array}$ & $\begin{array}{c}\text { Trans } \\
\text { Wareh }\end{array}$ & Info & $\begin{array}{c}\text { Fin \& } \\
\text { Ins }\end{array}$ & $\begin{array}{c}\text { Real } \\
\text { Estate }\end{array}$ & $\begin{array}{c}\text { Health } \\
\text { Care }\end{array}$ & $\begin{array}{c}\text { Entm \& } \\
\text { Rec }\end{array}$ & $\begin{array}{c}\text { Accom \& } \\
\text { Food }\end{array}$ \\
\hline Activity $^{k}$ & $\begin{array}{c}1.4047 \\
(1.18)\end{array}$ & $\begin{array}{c}0.4792 \\
(1.25)\end{array}$ & $\begin{array}{c}-0.0110 \\
(-0.04)\end{array}$ & $\begin{array}{c}-0.0919 \\
(-0.19)\end{array}$ & $\begin{array}{c}0.1470 \\
(0.47)\end{array}$ & $\begin{array}{c}0.0991 \\
(0.29)\end{array}$ & $\begin{array}{c}-0.6067^{* *} \\
(-2.39)\end{array}$ & $\begin{array}{r}-1.1937 \\
(-1.11)\end{array}$ \\
\hline $\mathrm{AD} \times$ Activity $^{k}$ & $\begin{array}{c}-0.0016 \\
(-1.65)\end{array}$ & $\begin{array}{c}-0.0005 \\
(-1.49)\end{array}$ & $\begin{array}{c}-0.0000 \\
(-0.10)\end{array}$ & $\begin{array}{c}0.0002 \\
(0.48)\end{array}$ & $\begin{array}{c}-0.0001 \\
(-0.34)\end{array}$ & $\begin{array}{c}-0.0001 \\
(-0.45)\end{array}$ & $\begin{array}{c}0.0005^{* * *} \\
(2.71)\end{array}$ & $\begin{array}{c}0.0016^{*} \\
(1.76)\end{array}$ \\
\hline
\end{tabular}

Control for fund dummy and time dummy, Obs $=6351, \operatorname{Adj} R^{2}=0.089$

\begin{tabular}{|c|c|c|c|c|c|c|c|c|c|}
\hline & $\begin{array}{c}\text { Amusement } \\
\text { Park }\end{array}$ & $\begin{array}{c}\text { Bookstore } \\
\text { News }\end{array}$ & $\begin{array}{l}\text { Child } \\
\text { Care }\end{array}$ & $\begin{array}{l}\text { Drinking } \\
\text { Places }\end{array}$ & $\begin{array}{l}\text { Fitness } \\
\& \text { Sports }\end{array}$ & $\begin{array}{l}\text { Full-service } \\
\text { Restaurant }\end{array}$ & $\begin{array}{l}\text { Personal } \\
\text { Care }\end{array}$ & $\begin{array}{l}\text { Café } \\
\& \text { Bar }\end{array}$ & $\begin{array}{l}\text { Bowling } \\
\text { \& Golf }\end{array}$ \\
\hline Activity & $\begin{array}{l}-1.579 \\
(-1.64)\end{array}$ & $\begin{array}{c}-0.796 * * * \\
(-2.92)\end{array}$ & $\begin{array}{l}-0.461 \\
(-1.45)\end{array}$ & $\begin{array}{c}-1.060^{* *} \\
(-2.11)\end{array}$ & $\begin{array}{c}-0.474^{* * *} \\
(-2.58)\end{array}$ & $\begin{array}{c}-0.521^{* * *} \\
(-3.59)\end{array}$ & $\begin{array}{l}-0.211 \\
(-0.68)\end{array}$ & $\begin{array}{c}-0.414^{* *} \\
(-2.21)\end{array}$ & $\begin{array}{l}-0.749 \\
(-1.13)\end{array}$ \\
\hline $\mathrm{AD} \times$ Activity & $\begin{array}{c}0.0005 \\
(0.99)\end{array}$ & $\begin{array}{c}0.0006^{* *} \\
(2.51)\end{array}$ & $\begin{array}{c}0.0004 \\
(1.53)\end{array}$ & $\begin{array}{c}0.0006^{*} \\
(1.76)\end{array}$ & $\begin{array}{c}0.0005^{* * *} \\
(3.45)\end{array}$ & $\begin{array}{c}0.0005^{* * *} \\
(4.45)\end{array}$ & $\begin{array}{c}0.0002 \\
(0.81)\end{array}$ & $\begin{array}{c}0.0005^{* * *} \\
(3.22)\end{array}$ & $\begin{array}{c}0.0007 \\
(1.41)\end{array}$ \\
\hline Fund FE & $\mathrm{Y}$ & $\mathrm{Y}$ & $\mathrm{Y}$ & $\mathrm{Y}$ & $\mathrm{Y}$ & $\mathrm{Y}$ & $\mathrm{Y}$ & $\mathrm{Y}$ & $\mathrm{Y}$ \\
\hline Time FE & $\mathrm{Y}$ & Y & $\mathrm{Y}$ & Y & $\mathrm{Y}$ & $\mathrm{Y}$ & $\mathrm{Y}$ & $\mathrm{Y}$ & $\mathrm{Y}$ \\
\hline Obs & 674 & 2361 & 4761 & 2047 & 10929 & 12114 & 4038 & 13888 & 1183 \\
\hline $\operatorname{Adj} R^{2}$ & 0.026 & 0.100 & 0.111 & 0.064 & 0.104 & 0.107 & 0.074 & 0.112 & 0.071 \\
\hline
\end{tabular}




\section{Table 11: Robustness Test: Fund Management with Sub-Advisors}

In this table, we reexamine the impact of lockdown on fund returns conditioning on whether a fund's management uses sub-advisors.

$$
\begin{aligned}
\text { Ret }_{m t}= & \alpha+\beta * \text { Lockdown }_{m t}+\zeta * \text { AD }_{m}^{\text {Mar2019 }} \times \text { Lockdown }_{m t} \times \text { SubAdvisor } \\
& +\gamma * A D_{m}^{\text {Mar2019 }} \times \text { Lockdown }_{m t}+\delta * \text { Lockdown } \times \text { SubAdvisor }+\alpha_{m}+\alpha_{t}+\varepsilon_{m t} .
\end{aligned}
$$

SubAdvisor is a dummy variable if a fund's management uses sub-advisors. All other variables in

\begin{tabular}{|c|c|c|c|c|c|}
\hline & $(1)$ & $(2)$ & & $(3)$ & $(4)$ \\
\hline Lockdown & $\begin{array}{c}-0.1541 \\
(-0.21)\end{array}$ & $\begin{array}{c}-0.1598 \\
(-0.29)\end{array}$ & Footprint & $\begin{array}{c}-2.8292^{* * *} \\
(-4.79)\end{array}$ & $\begin{array}{c}-1.4805^{* * *} \\
(-3.22)\end{array}$ \\
\hline AD*Lockdown & $\begin{array}{c}0.0015^{* * *} \\
(3.11)\end{array}$ & $\begin{array}{c}0.0008^{* *} \\
(2.23)\end{array}$ & AD*Footprint & $\begin{array}{c}0.0022^{* * *} \\
(3.98)\end{array}$ & $\begin{array}{c}0.0012^{* * *} \\
(3.08)\end{array}$ \\
\hline AD*Lockdown*SubAd & $\begin{array}{c}0.0002 \\
(0.29)\end{array}$ & $\begin{array}{c}-0.0003 \\
(-0.72)\end{array}$ & $\mathrm{AD}^{*}$ Footprint*SubAd & $\begin{array}{c}-0.0005 \\
(-0.60)\end{array}$ & $\begin{array}{c}-0.0007 \\
(-1.50)\end{array}$ \\
\hline Lockdown*SubAdvisor & $\begin{array}{c}-0.4289 \\
(-0.52)\end{array}$ & $\begin{array}{c}0.0843 \\
(0.16)\end{array}$ & Footprint*SubAdvisor & $\begin{array}{c}0.5115 \\
(0.60)\end{array}$ & $\begin{array}{c}0.7017 \\
(1.25)\end{array}$ \\
\hline Fund Dummy & $\mathrm{Y}$ & $\mathrm{Y}$ & Fund Dummy & $\mathrm{Y}$ & $\mathrm{Y}$ \\
\hline Time Dummy & $\mathrm{Y}$ & $\mathrm{Y}$ & Time Dummy & $\mathrm{Y}$ & $\mathrm{Y}$ \\
\hline Obs & 14897 & 14885 & Obs & 15949 & 15935 \\
\hline $\operatorname{Adj} R^{2}$ & 0.886 & 0.112 & $\operatorname{Adj} R^{2}$ & 0.885 & 0.106 \\
\hline
\end{tabular}
the regressions are defined as in Table 2. The sample period is from January 2019 to June 2020. 


\section{Table 12: Robustness Test for Fund Investment}

In this table, we reexamine the impact of lockdown on fund portfolio's asset allocation using the setup in Table 6 . Instead of using the continuous variable $D_{i m}$ to measure the fund-firm distance, we introduce a dummy variable $L O C A L_{i m}$, which is equal to one if a firm is within 250 miles of the holding fund's headquarter and zero if it is more than 1250 miles away from the holding fund's headquarter. The dependent variable is the excess weight a fund investing in a given stock relative to its benchmark. All other variables in the regressions are defined as in Table 6. The sample period is from January 2019 to June 2020.

\begin{tabular}{lllll}
\hline & $(1)$ & $(2)$ & $(3)$ & $(4)$ \\
\hline Lockdown $_{m t}$ & 0.0101 & 0.0095 & 0.0088 & 0.0082 \\
& $(1.43)$ & $(1.35)$ & $(1.25)$ & $(1.17)$ \\
LOCAL*Lockdown $_{m t}$ & $-0.0121^{*}$ & $-0.0107^{*}$ & $-0.0129^{* *}$ & $-0.0114^{*}$ \\
& $(-1.96)$ & $(-1.71)$ & $(-2.10)$ & $(-1.83)$ \\
Firm Lockdown & & $0.0095^{*}$ & & 0.0078 \\
& & $(1.89)$ & & $(1.56)$ \\
Firm RET & & & $0.0014^{* * *}$ & $0.0014^{* * *}$ \\
& & & $(12.91)$ & $(12.85)$ \\
Firm SIZE & & $0.0127^{*}$ & $0.0130^{*}$ \\
& & & $(1.75)$ & $(1.77)$ \\
Firm ROA & & $0.0970^{* * *}$ & $0.0962^{* * *}$ \\
& & & $(4.89)$ & $(4.85)$ \\
Fixed Effects & & & $\mathrm{Y}$ \\
Industry $\times$ Time & & $\mathrm{Y}$ & $\mathrm{Y}$ & $\mathrm{Y}$ \\
Firm & $\mathrm{Y}$ & $\mathrm{Y}$ & $\mathrm{Y}$ & $\mathrm{Y}$ \\
Fund & $\mathrm{Y}$ & 1070581 & 1072449 & 1057277 \\
Obs & 1086099 & 0.549 & 0.547 & 0.548 \\
Adj $R^{2}$ & 0.547 & &
\end{tabular}

